\title{
NUEVAS APORTACIONES AL ESTUDIO DE LAS DEFENSAS DEL CAMPO DE SANCTI PETRI EN SAN FERNANDO (CÁDIZ), EN EL CONTEXTO DE LA GUERRA DE INDEPENDENCIA
}

\section{NEW CONTRIBUTIONS TO THE STUDY OF THE DEFENSES IN CAMPO DE SANCTI PETRI IN SAN FERNANDO (CÁDIZ), IN THE CONTEXT OF THE WAR OF INDEPENDENCE}

\section{Francisco GHERSI GARCÍA}

Comandante de Artillería, miembro del equipo "Proyecto Torregorda - Camposoto", Universidad de Cádiz Correo electrónico: fghersig@gmail.com

Resumen: En este trabajo se realiza un estudio historiográfico de las defensas del llamado Campo de Sancti Petri, actualmente denominado Punta del Boquerón, dentro del término municipal de San Fernando (Cádiz); existentes en la zona durante la Guerra de Independencia. Con ello se pretende aportar y aclarar conocimientos sobre la evolución de las baterías que se instalaron en la Punta del Boquerón hasta la Guerra de Independencia, sin entrar en los detalles de las operaciones militares y enfocando la investigación en la evolución de su construcción, a través de la cartografía y documentos de la época. Algunas de estas fuentes documentales se corresponden con documentación inédita del archivo de la antigua Comandancia de Ingenieros del Gobierno Militar de Cádiz. Cajón 5, Legajo 76, la cual puede resultar clave para entender la evolución de esta parte de las defensas de la Isla de León.

Palabras Clave: Campo de Sancti Petri, Punta del Boquerón, Aspiroz, Urrutia, Sangenis, Batería de la Barca, Guerra de Independencia, Luis de Landaburu.

\begin{abstract}
In this work a historiographic study of the defenses of the so-called Campo de Sancti Petri, currently called Punta del Boquerón, within the municipality of San Fernando (Cádiz), existing in the area during the War of Independence, is carried out. This is intended to provide and clarify knowledge about the evolution of the defenses that were installed in Punta del Boquerón until the War of Independence, without going into the details of military operations and focusing research on the evolution of their construction, through of cartography and documents of the time. Some of these documentary sources correspond to unpublished documentation from the archive of the old Engineers Command of the Military Government of Cádiz. Box. 5, File 76, which may be key to understanding the evolution of this part of the defenses of Isla de León.
\end{abstract}

Keywords: Campo de Sancti Petri, Punta del Boquerón, Aspiroz, Urrutia, Sangenis, Batería de la Barca, Guerra de Independencia, Luis de Landaburu.

Sumario: 1. Introducción. 2. Antecedentes. 3. Guerra de Independencia. 4. Los reductos ingleses. 5. Conclusiones. 5.1. Batería de Azpiroz. 5.2. Batería de Urrutia. 5.3. Batería de la Marina. 5.4. Batería de Sangenis. 5.5. Reductos Ingleses. 6. Bibliografía. 7. Anexo.

\section{Introducción}

La Punta del Boquerón se sitúa al sur del término municipal de San Fernando, en la provincia de Cádiz, es la punta arenosa de una flecha litoral que conforma la playa que se extiende desde Cádiz hasta la desembocadura del caño de Sancti Petri, la cual actualmente está cubierta por una línea de dunas vírgenes emergidas del Atlántico.

Este trabajo se centra en el estudio de la car- tografía y de los documentos inéditos originales como fuente de información de los restos de construcciones de las defensas militares ejecutadas con motivo de la Guerra de Independencia, gracias a las cuáles podremos hacer cambiar la percepción de lo conocido hasta ahora. Se han vertido ríos de tinta sobre las baterías de defensa del Sitio de Cádiz -muchos trabajos acertados, pero otros no tanto-; sobre todo en cuanto a la situación topográfica, denominación y momento de su cons- 
trucción. Para intentar dar luz sobre este asunto, en este trabajo vamos a intentar aclarar algunas imprecisiones que se han publicado sobre estas defensas. Para ello, este artículo se fundamenta documentalmente en el Archivo de la Comandancia de Ingenieros del Antiguo Gobierno Militar de Cádiz; especialmente en el cajón 5, legajo 76.

Nota: Los textos en cursiva se corresponden con la trascripción literal de los documentos consultados.

Hay que hacer constar que, en la cartografía antigua, los cartógrafos e ingenieros militares a veces solían realizar copias de planos anteriores o incluso usar los planos originales para, sobre ellos, dibujar nuevos proyectos que se presentaban a las autoridades superiores en fecha posterior, lo que puede dar origen a dataciones erróneas, como ha ocurrido en alguno de los casos que nos ocupa y que pretendemos aquí rebatir. En este sentido, cuando se hace referencia a algún plano cartográfico hay que tener en cuenta que muchas veces se toma al pie de la letra la fecha del plano para datar lo que muestra. Incluso en otras ocasiones nos encontramos con planos sin fecha que se le ha asignado una datación que, tras un examen crítico, no le puede corresponder; como por ejemplo le ocurre a un plano que representa a las Baterías de Azpiroz, Urrutia y Sangenis que ha sido datado en 1809 (Archivo General Militar de Segovia. Colección: ES-DFAMD. Signatura: Carpeta 39, Plano 402) y que, como veremos a lo largo de este trabajo, es a todas luces incorrecto.

\section{Antecedentes}

Las obras de defensa son las construcciones que primeramente se dibujan en los planos, sobre todo si son las trazadas por los oficiales militares del Cuerpo Militar de Ingenieros. En nuestro caso objeto de estudio -la Punta del Boquerón- la cartografía nos evidencia el proyecto de instalación de este tipo de edificaciones a partir del año 1739. Con anterioridad a esa fecha, no se describe ninguna defensa en dicho lugar, apareciendo en los planos conservados de fechas anteriores solo en algún caso el paso de barcas y alguna construcción anexa a la misma, pero sin ninguna indicación de que sea claramente algún tipo de obra defensiva.

De 1739 es el primer documento cartográfico que se estudia, plano de autor desconocido, sin título ni descripción sobre él, y que representa las fortificaciones desde la ciudad de Cádiz a Sancti-Petri, y en la que se muestra una batería proyectada de diez cañones en este último lugar y que se muestra en la figura 1, (Ministerio De Cultura y Deporte. Archivo General de Simancas. Signatura: MPD, 65, 081).

Los datos de la fecha del plano están extraídos de los documentos archivados junto a él, donde se indica la data de 24 de agosto de 1739 en una carta que acompaña al plano, de Juan Fernando Leroy de Ville y Cambier, Conde de Roydeville, quién desde el 6 de agosto de 1737 era el Gobernador y Capitán General de las costas del mar Océano, Ejército y reinos de Andalucía (Figura 1).

En ese documento, tenemos la primera constancia gráfica de un proyecto de defensa erigida sobre este espacio, el cual concuerda con el que fue presentado por el Ingeniero Bartolomé Amphoux en el proyecto que, con fecha 6 de octubre de 1739, remite el Conde de Roydeville al Marqués de Uztariz, Secretario de Estado y Guerra de Felipe V (Ministerio de Cultura y Deporte, Archivo General de Simancas. Signatura: MPD, 30, 051 p_1b). Junto a ese documento se remitió otro proyecto añadido sobre el mismo plano en el que el propio Conde proponía una modificación de la gola original de Amphoux, en la que se aprovechaba todo el ancho de la batería (Figuras 2 y 3). La batería original proyectada por Amphoux era semicircular con diez cañoneras con sus correspondientes plataformas y once merlones; la gola estaba cerrada con cuartel para la infantería, cuarto del oficial, cuarto de los artilleros, cuarto de pertrechos, cocinas para el oficial y la tropa, entrada con rastrillo cerrada con un muro aspillerado al exterior, cuadra para caballería y almacén para la pólvora. El texto del proyecto original es el que está enmarcado en el plano de la izquierda de la figura 2 .

En el proyecto de modificación añadido que realiza el Conde de Roydeville (Ministerio de Cultura y Deporte, Archivo General de Simancas. Signatura: MPD, 30, 051 p_2b), propone una gola que cierra totalmente la batería por detrás e incluye unas letrinas, el texto explicativo lo escribe directamente sobre el plano de Amphoux, D. Cuerpo de Guardia y cozina del oficial. E. Cuerpo de guardia de los artilleros. F. Cuarto para pertrechos. G. Letrinas. H. Cuerpo de guardia para la infanteria. I. Cozina para dha guardia, mientras que la planta de la nueva gola lo realiza sobre un recortable abatible pegado al plano original mediante una pestaña, ambos detalles están recuadrados en plano de la derecha de la figura 2 . 


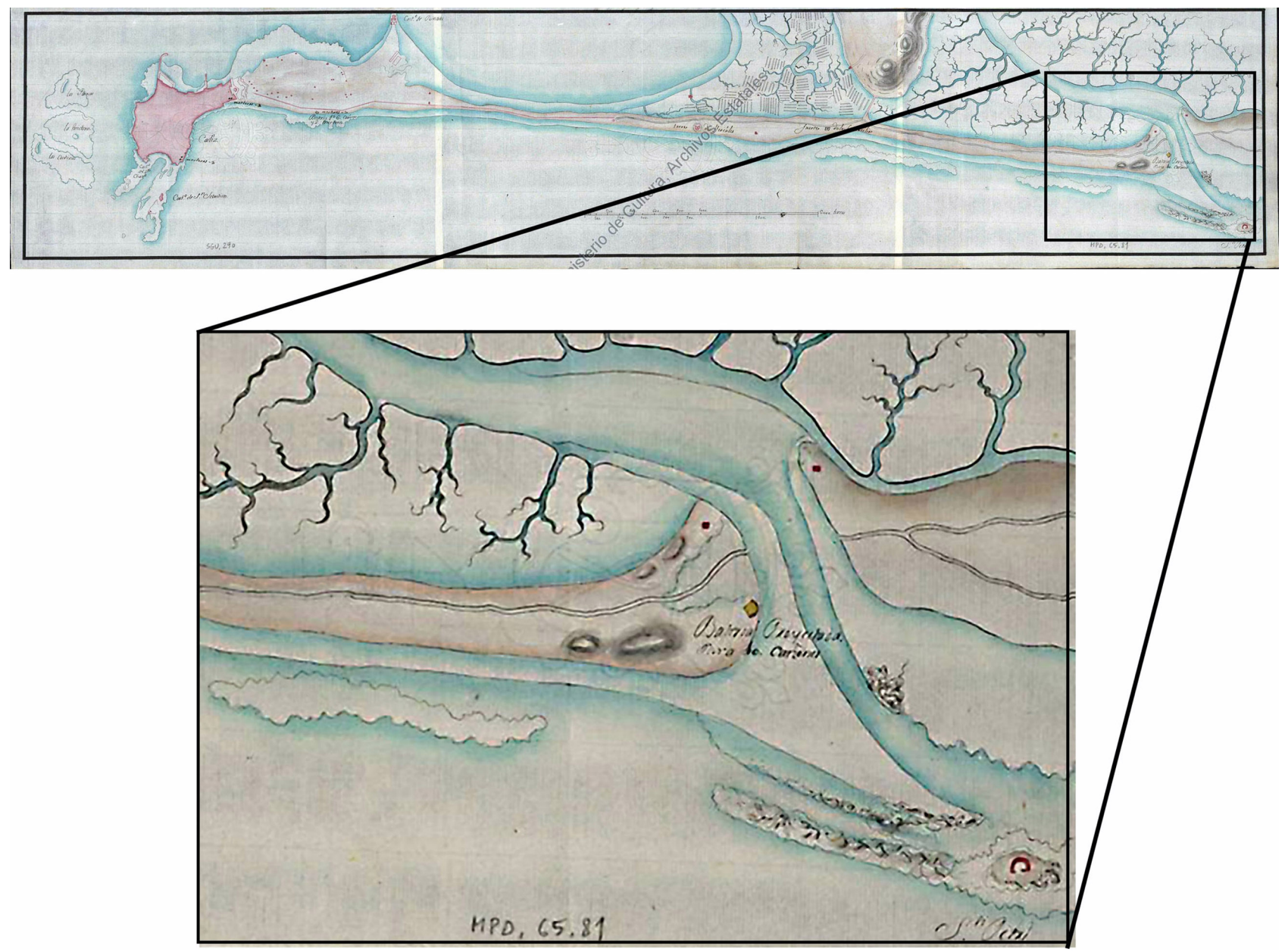

Figura 1. Plano de 1739 y detalle del mismo, donde se muestra el primer proyecto de defensa de la zona con el texto "Batería proyectada para 10 cañones". (Fuente: Ministerio de Cultura y Deporte, Archivo General de Simancas. Signatura: MPD, 65, 081

Unas décadas más tarde, en concreto en 1766, Antonio de Gaver, Ingeniero Director de la Plaza de Cádiz le remite al Gobernador de Cádiz, José de Sentmenat, un plano en relación con una "revista realizada de la frontera y puertos fortificados del Reino para libertar a Cádiz de un Bombardeo y ataque por mar" (Ministerio de Cultura y Deporte, Archivo General de Simancas. Signatura: MPD, 071, 059). Debemos resaltar cómo en este documento aparece esta batería ya construida, aunque sin detallar ninguna denominación (Figura 3).

El Coronel Ingeniero Juan Caballero firma, con fecha del 18 de diciembre de 1770, un plano de las cercanías de Cádiz y su bahía que muestra dos proyectos, "el uno para precaver la cabeza del Puente de Suazo, y el otro las avenidas que conducen por tierra al Castillo de Matagorda a fin de asegurar estos dos importantes puestos" (Ministerio de Cultura y Deporte, Archivo General de Simancas. Signatura: MPD, 33, 054). Este plano se conserva dentro de una carpetilla que se intitula Cádiz. Año 1770.
Mapa de las cercanías de esta Plaza y su Bahía con dos proyectos para la defensa del Puente de Suazo y Castillo de Matagorda por D. Juan Caballero. Lo que nos interesa de este plano para nuestro estudio, no es en sí el sistema defensivo del puente, sino la batería que se muestra en la playa de Sancti Petri y que la denomina Batería de la Voca del Río (sic) y que podemos apreciar en el detalle de dicho plano que se muestra en la figura 4 (Figura 4).

Observando el plano podemos constatar que esta defensa, construida para cubrir la entrada de barcos del mar hacia el Caño de Sancti Petri, es sin duda la batería proyectada por Amphoux en 1739, siguiendo las mismas pautas de las construidas en Cádiz como las de la Primera y Segunda Aguada, con la gola cerrada para su mejor defensa.

Unos años más tarde, en el "Plano que manifiesta la entrada del Río Sancti Petri su sondeo la situación del Castillo del mismo nombre y aguas que defiende. Cádiz 13 de agosto de 1797 de Josef del Pozo" (Archivo General Militar de Segovia. Colec- 

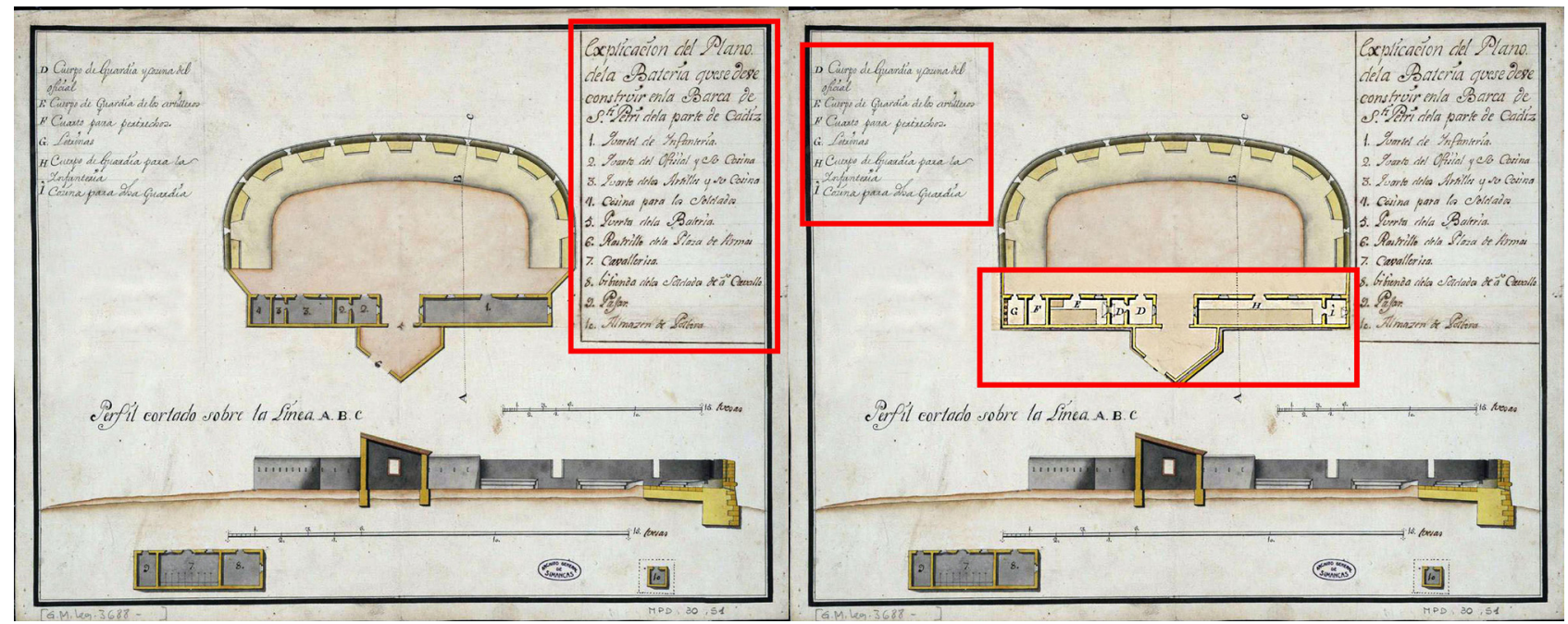

Figura 2. A la izquierda, Plano de la Batería que se deve (sic) construir en la Barca de S[anc]ti Petri de la parte de Cádiz. A la derecha, proyecto añadido del Conde de Roydeville. (Fuente: Ministerio de Cultura y Deporte, Archivo General de Simancas. Signatura: MPD, 30, 051 p_1b).

ción: ES-DFAMD. Signatura: Carpeta 38, Plano 387 p.1), se muestra otra batería, y su autor la define en este caso como "batería arruinada", ver figura 5. La similitud de la ubicación, así como de los detalles constructivos nos lleva a pensar que dicha estructura se corresponde con la misma batería mostrada en los anteriores planos y que, a pesar de haber transcurrido solo 35 años desde su construcción, tuvo que ser desechado su mantenimiento lo que la llevó a su ruina (Figura 5).

Antonio Hurtado en su Relación de la consistencia de la plaza de Cádiz y Fuertes de la comprensión de esta Isla, cuyo nombre propio es el que antiguamente tuvo y ahora Isla de León (Pérez, 1978: 257), documento fechado el 23 de junio de 1803, da la clave de la fecha de su construcción, tratando sobre la posición de Sancti-Petri dice que "la batería construida por la Marina en 1762, frente a la caseta de Rentas, estaba en el ángulo que forma la orilla del Río con la costa y playa de Santa María, se tituló de la "Barca" [y] está bien colocada al objeto de batir las embarcaciones enemigas por la proa al mismo tiempo que el Castillo lo ejecuta por el costado". Desgraciadamente esta fuente no especifica su estado de conservación, si bien pensamos sin duda alguna que se refiere a la misma batería proyectada por Amphoux y que, según Hurtado, no se debió materializar su construcción hasta ese año de 1762.

En este mismo informe, cita más adelante "la defensa de Cádiz, en un posible ataque por tierra, estaba en el Río o Caño de Sancti-Petri. Como en las tres leguas que de aquí distan a Cádiz no hay ningu- na defensa, por aquí puede introducirse sin estorbo en el pueblo de la Isla de León cualquier enemigo que hubiese desembarcado en dicha playa y dirigirse a Cádiz igualmente" (Pérez, 1978: 266); gracias a lo cual se desprende la clara necesidad de mejorar o reformar dichas defensas.

A través de estos documentos, y fundamentalmente de los cartográficos, constatamos el deterioro de la batería motivado principalmente por el desuso; su posterior reactivación y los cambios de nombre que fue sufriendo, aspecto éste muy arraigado en la tradición española, pues según el devenir político o militar era usual el cambio en la nomenclatura de estas estructuras, a imagen y semejanza de los cambios en los rótulos de calles, lugares o establecimientos militares que observamos en la actualidad. Sin embargo, una idea debe quedar clara, a pesar de esos cambios en su nomenclátor su posición cartográfica se mantuvo invariable desde 1762 .

\section{Guerra de Independencia}

Desde el momento de la declaración de guerra en 1808 a los franceses y ante el avance de sus ejércitos sobre Andalucía, se fueron acelerando los proyectos de ampliación y mejora de las defensas de la Isla de León, en un principio centradas en el interior de la bahía, en la Carraca y en el Puente Zuazo, para extenderse más tarde por el perímetro del caño de Sancti Petri.

Francisco Hurtado, Teniente Coronel de Ingenieros y vocal de la Junta de Defensa de la Plaza de Cá- 


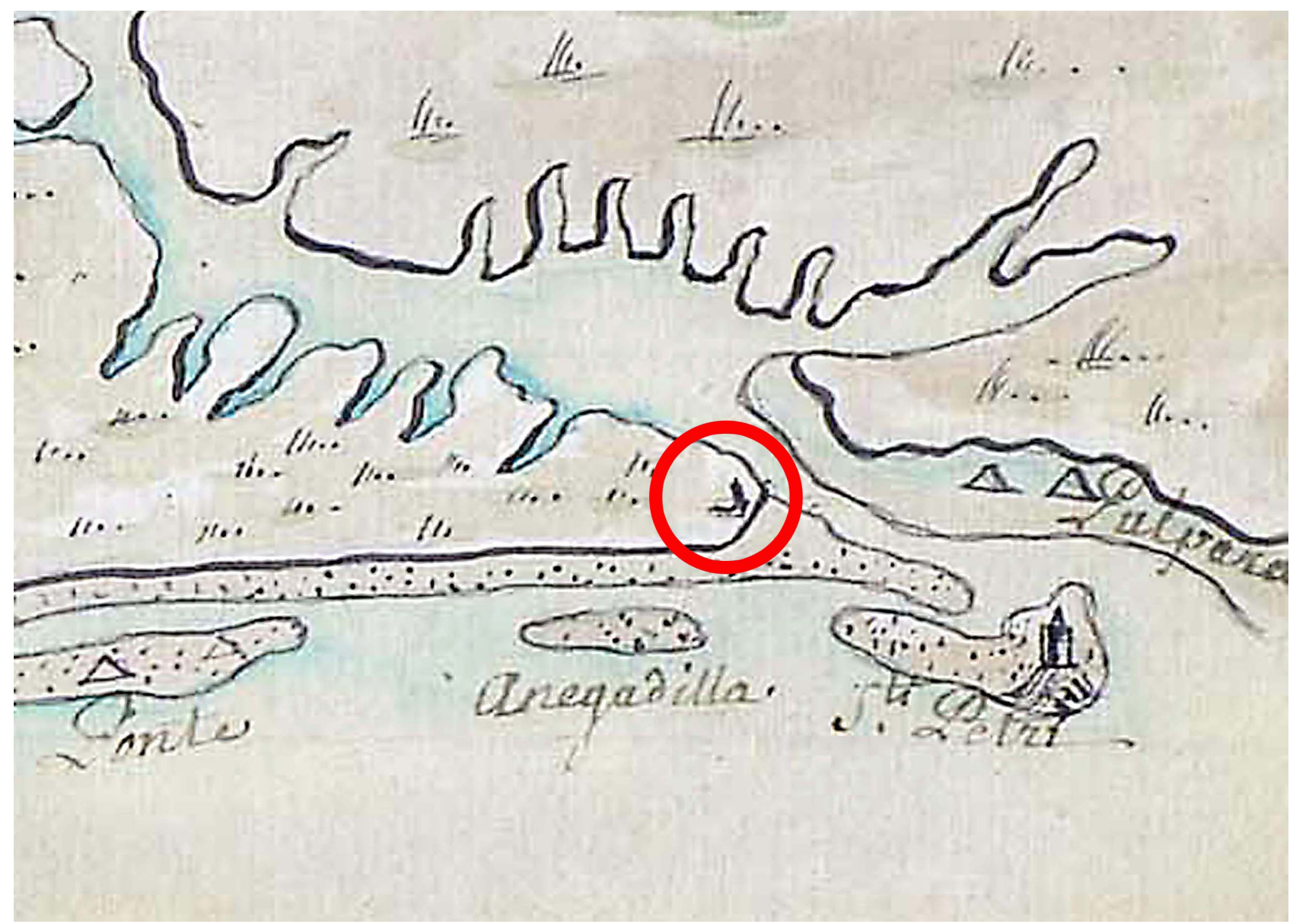

Figura 3. Detalle del plano de Antonio de Gaver de 17 de enero 1766 sobre "la revista realizada de la frontera y puertos fortificados del Reyno", donde ya se muestra la Batería construida (resaltada en círculo rojo). (Fuente: Ministerio de Cultura y Deporte, Archivo General de Simancas. Signatura: MPD, 071, 059).

diz, en mayo de 1809 desarrolla un proyecto de defensa de la zona en el plano Cerro de los Mártires, río Arillo, embocadura del sur de Sancti Petri y terrenos inmediatos donde dibuja en el Campo de Sancti Petri dos posiciones (Figura 6); una la denomina Batería de la Marina arruinada, sin duda para aclarar en la descripción la situación en la que se encontraba la misma, refiriéndose a la Batería de la Marina anteriormente citada; y una segunda construcción que llama de Los Inválidos, junto al paso de la barca , sin aclararnos si es otra batería o si pudiera tratarse de la caseta de rentas citada por Antonio Hurtado (Regimiento de Artillería de Costa no 4, copia).

Durante ese año de 1809, se mejoraron las baterías del complejo del Puente Zuazo y de la Carraca, y fue a partir de la entrada en la Isla de León del ejército de Extremadura al mando del Duque de Alburquerque entre el 2 y el 4 de febrero de 1810, y ante la presencia del ejército francés, cuando se aceleraron los proyectos y las obras de construcción de nuevas defensas y la mejora de todas las existentes. En este sentido en Sancti Petri solo se mantenía en ese momento "una batería a barbeta, con los cañones sin montar tirados por la arena" (Torrejón, 2008), correspondiéndose seguramente con los restos de la antigua batería de la marina arruinada, citada por Hurtado.

El día 13 de febrero se empezaron en Sancti-Petri los trabajos de fortificación, artillado y seguridad, por considerarse esta posición uno de los puntos críticos de la zona de operaciones. Entre los trabajos de fortificación se construyó una batería nueva junto a la barca de Sancti Petri, en el mismo lugar que Hurtado nombra como Los Inválidos; estando edificada con un solo orden de altura de cañones, como veremos más adelante.

Sin entrar en los detalles harto conocidos de las desavenencias del Teniente General Duque de Alburquerque con la Junta de Cádiz, el Consejo de Regencia lo nombró embajador extraordinario en Inglaterra, designando asimismo como Inspector General de Infantería y Milicias de toda España a 


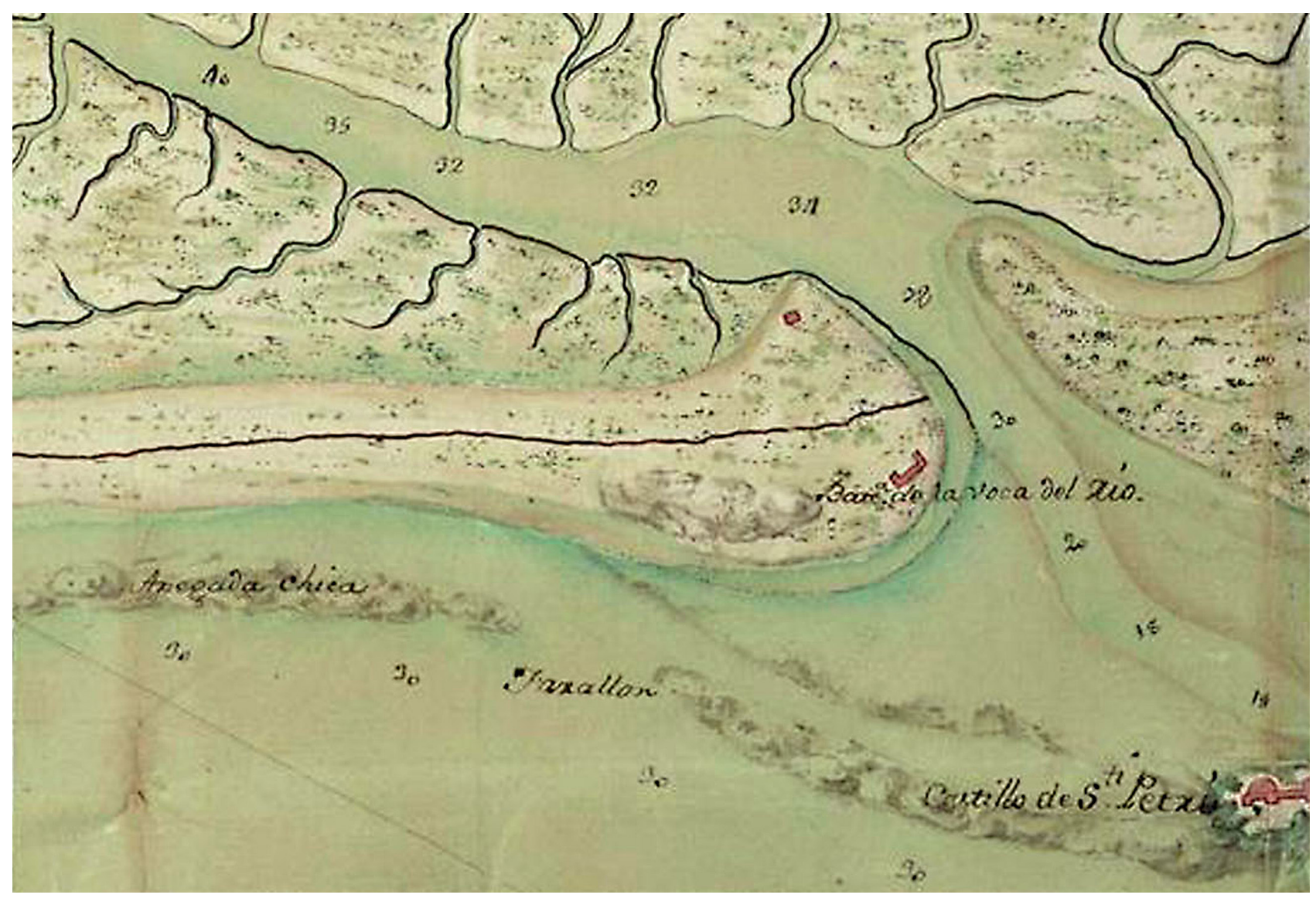

Figura 4. Detalle del plano de fecha 18 de diciembre de 1770. Mapa de las cercanías de esta Plaza y su Bahía con dos proyectos para la defensa del Puente de Suazo y Castillo de Matagorda por D. Juan Caballero.

(Fuente: Ministerio de Cultura y Deporte, Archivo General de Simancas. Signatura: MPD, 33, 054).

Joaquín Blake, quién llegó a Cádiz desde Murcia el 24 de abril, haciéndose cargo de las fuerzas que defendían la plaza como General en Jefe y retomando inmediatamente con más ímpetu los proyectos de mejora de las defensas. En este contexto, pocos días después, Manuel Zappino, Comandante General del Cuerpo de Ingenieros del Ejército de Extremadura, del que también se ha hecho cargo Blake, remitió una orden a todos sus subordinados implicados en las obras de defensa en la que:

Se previene a todos los oficiales del Real Cuerpo de Ingenieros que con presencia de los reconocimientos y observaciones que hayan en los puntos a que están destinados, manifiesten sus reflexiones acerca de las obras que consideren necesarias para la mejor defensa de ellos, como de las mejoras que sean susceptibles de ejecutarse, expresando las ventajas o defectos que encuentren, a fin de proceder con estos datos a la ejecución de los proyectos que sean más convenientes.
Como consecuencia de esta misiva se elevaron varios proyectos y propuestas, entre las que destacamos la del capitán de Ingenieros Luis de Landaburu fechada el 30 de abril de ese año, relativa a la playa de Sancti Petri, en cuyas obras de defensa estaba destinado y que denomina Breve idea del aumento de defensa que convendría ejecutar en la playa llamada de Sancti Petri (anexo 1). Este estudio se acompaña de un croquis donde refleja gráficamente su proyecto (Figura 7). Además, junto a reflexiones sobre posibles ataques del enemigo y refiriéndose a las defensas con las que se cuenta, dice:

Nuestra defensa como se halla hoy día, consiste principalmente, en la Artillería del Castillo de Sancti Petri que flanquea el camino de Chiclana, en la batería vieja y las cañoneras. Pues las otras dos baterías no pueden usar sus fuegos con el acierto necesario para detener las obras enemigas, y la trinchera únicamente puede servir contra sorpresas. 


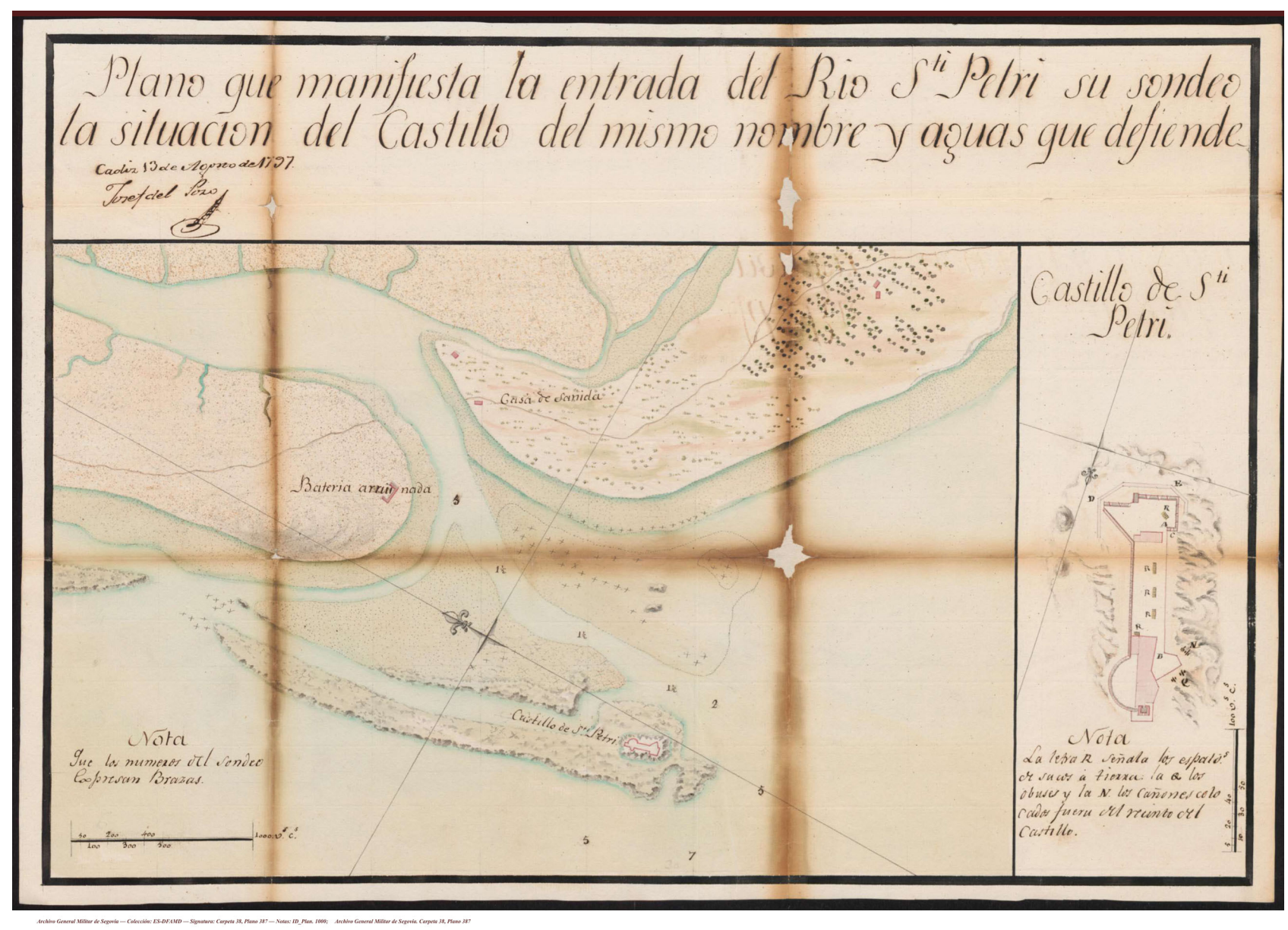

Figura 5. Plano que manifiesta la entrada del Río Sancti Petri, su sondeo, la situación del Castillo del mismo nombre y aguas que defiende. Cádiz 13 de agosto de 1797. Josef del Pozo. (Fuente: Archivo General Militar de Segovia. Colección: ES-DFAMD. Signatura: Carpeta 38, Plano 387).

Aparte del Castillo de Sancti Petri, la "Batería Vieja" y las cañoneras de las fuerzas sutiles, observamos que cita como defensas existentes en ese momento, otras dos baterías y una trinchera, que son las obras de fortificación que comenzó Alburquerque dos meses antes y que, a juicio de este capitán, no cumplían con el objetivo previsto.

En párrafos posteriores propone que:

No será pues en balde, el trabajo y cuidado que se empleen en aumentar la batería vieja, que se debe considerar como decisiva en la defensa, y este aumento deberá llevarse al punto de montar en ella 30 o 35 piezas, y elevarla 12 o 15 pies para que domine con facilidad el terreno que ha de batir. El espesor de sus parapetos deberá ser de 21 pies; su revestimiento el ordinario de plaza, y su gola deberá cerrarse; en una palabra, debe ser una obra capaz de llenar el grande objeto al que se destina.
Y por otro lado:

La batería nueva tiene dos objetos, batir el Caño del Molino y la avenida de Chiclana. El $1^{o}$ lo llena debidamente; pero no así el $2^{\circ}$ por su cortísima elevación. Se deberán pues elevar las cinco primeras piezas destinadas a este objeto, hasta conseguir el fin propuesto; esto es, unos 10 pies. La batería de obuses, no puede coadyuvar a el sino con fuegos inciertos por su elevación, cuya razón empeña tanto mas el aumento de la batería vieja...

De esta exposición se colige que, a finales de abril de 1810, había una batería "vieja" a barbeta artillada, una batería "nueva" también artillada con todos los cañones a la misma altura y una batería "de obuses", todas ellas sin asignación de nomenclatura. Al hacer la comparación crítica entre el plano de Hurtado de 1809 y el croquis de Lan- 
daburu de 1810 podemos deducir claramente que la batería de la Marina arruinada se corresponde con la batería vieja, la edificación de los Inválidos con la situación de la batería nueva y cómo la batería de obuses se situó más al norte de las dos anteriores. Insistir que esas dos últimas baterías mencionadas debieron ser construidas a partir del 19 de febrero de 1810, como se ha comentado anteriormente, fecha de inicio de las obras de mejora de las defensas de Sancti Petri que propuso Alburquerque, sin poder ofrecer por el momento más detalles sobre su construcción (Figura 7).

La exposición continúa con más propuestas de mejoras:

La batería nueva y la de obuses convendría estuviesen cerradas en los términos que la batería vieja, y rodearlas de foso y estacada para el caso posible aunque remotísimo de una sorpresa. Todas se deberían unir con una línea bien construida con su estacada, y esta debería continuarse en la baja mar hasta la profundidad de dos varas y media, con lo cual quedaría una línea continua cuyos flancos estarían perfectamente apoyados.

Es de indispensable y urgente necesidad, espaldonar por de pronto el campamento de la tropa, continuando la comunicación de la batería nueva a la vieja por la derecha, hasta que quede cubierto el Campo, y llenarlo todo de dados para sortear las granadas, que impunemente podrá arrojar el enemigo cuando quiera; y digo por el pronto, porque concluidas las obras deberá trasladarse el Campo fuera del tiro del cañón enemigo, sin quedar en la línea y baterías mas que la guarnición necesaria; pues por mas espaldones que se construyan, en caso de un ataque es difícil evitar continuas desgracias, y cuando no la inquietud e incomodidades que son consiguientes a un fuego vivo y continuado.

Aquí Landaburu hace referencia al Campamento de las Tropas que guarnecen ese punto y que ocupaba gran parte del terreno por detrás de la línea de baterías y que en el estado de la fuerza de agosto de ese mismo año contaba con el Regimiento de Infantería de Línea de Canarias, el Batallón de Voluntarios de Honor de la Real Universidad de Toledo, el Regimiento de Infantería de Línea de
Trujillo, el Batallón de Infantería Ligera de Voluntarios de Campo Mayor y el Regimiento de Infantería de Línea de Murcia, conformando un contingente militar de más de dos mil soldados disponibles acampados en tiendas de campaña y barracones (AHN, Diversos-Colecciones,108,N.37). A estos habría que sumarle las unidades de ingenieros desplegadas en la zona y las dotaciones de artilleros de las baterías.

Como resumen del proyecto de Landaburu podemos destacar lo siguiente:

- Reformas que propone en la batería "Nueva": elevar a 10 pies $(2,8 \mathrm{~m})$ las cinco piezas de la derecha, por ser esta batería demasiado baja para cumplir su propósito, cerrarla por la gola y rodearla de foso y estacada.

- Reformas que propone en la batería "Vieja": aumentar su frente a 30 o 35 piezas, elevarla en su conjunto a 12 o 15 pies $(3,40$ o 4,20 m) y aumentar el espesor de sus parapetos a 21 pies $(5,85 \mathrm{~m})$. En este caso, más que una reforma, en realidad es un proyecto de nueva construcción.

Este documento junto con su croquis, se elevó por conducto reglamentario a través de su jefe inmediato Gonzalo Lorenzo y Cáceres, Teniente Coronel del Real Cuerpo de Ingenieros y Comandante de la $2^{\text {a }}$ Brigada de Ingenieros (destinada a las obras de defensa de la derecha de la línea), a Manuel Zappino, Comandante General del Cuerpo de Ingenieros del Ejército de Extremadura, con fecha 30 de abril, en el que glosa el estudio del capitán:

El discernimiento y atinado juicio con
que discurre este Oficial, hacen su plan
muy digno de toda atención, y aprecio, así
por la importancia del objeto, como por
lo reflexivo de la idea con que esta conce-
bido, hijas de muy buenos conocimientos
militares en general, y de una particular
aplicación al examen y estudio del ata-
que y defensa de aquel punto, Por tanto
le recomiendo muy particularmente, a
fin de que elevándole a la consideración
del Sr. General en Jefe de este Ejercito, no
quede obscurecido el merito de un oficial
estudioso y aplicado, y determine en con-
secuencia lo que juzgue por mas conve-
niente.

El 2 de mayo Manuel Zappino se lo remitió al Teniente General del Cuerpo de Ingenieros Anto- 


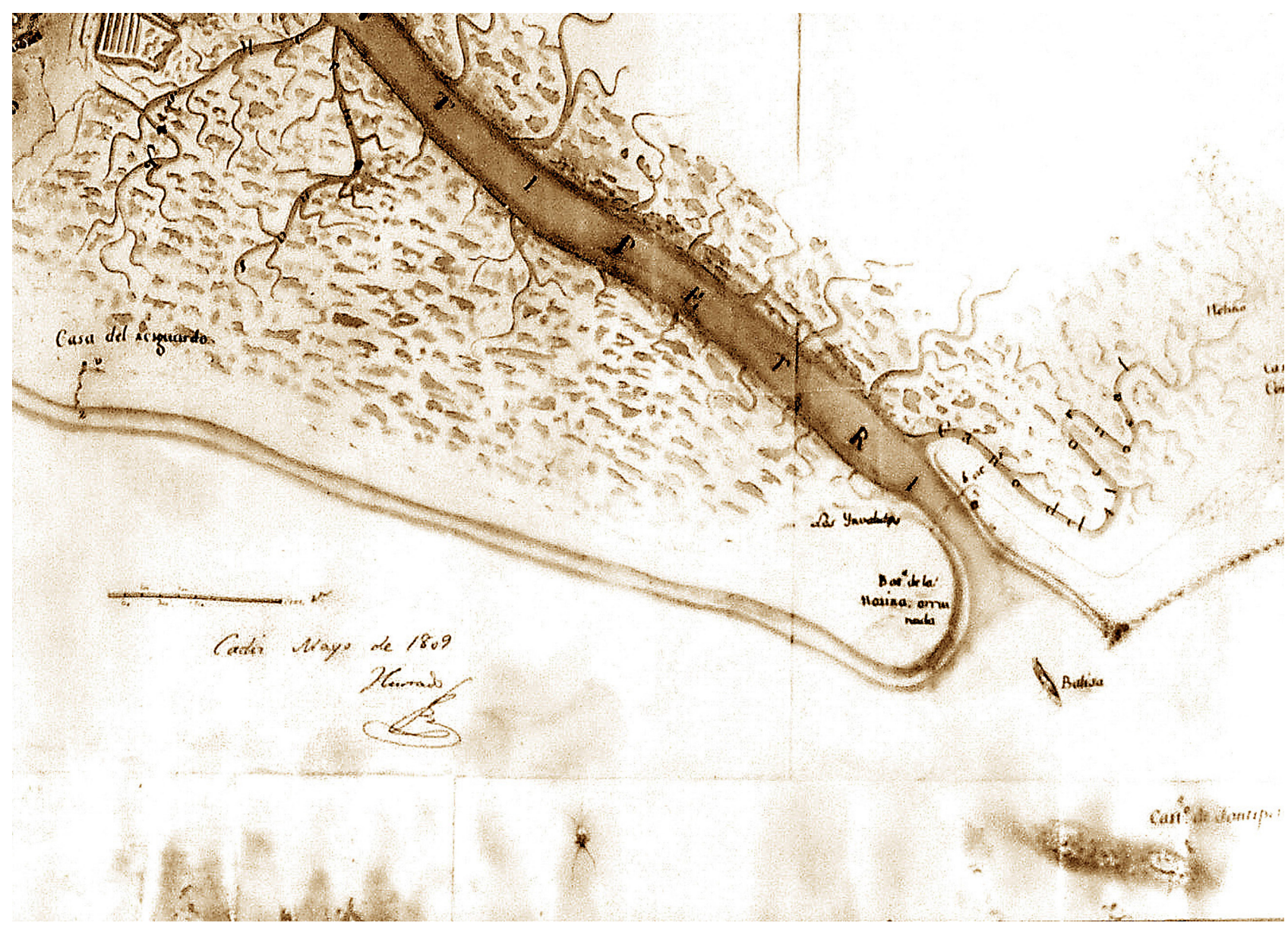

Figura 6. Detalle del plano de Francisco Hurtado "Cerro de los Mártires, río Arillo embocadura del sur de Sancti Petri y terrenos inmediatos”, 1809. (Fuente: Archivo RACTA 4).

nio Samper informándole asimismo que con fecha 1ํ de mayo lo había pasado al Exmo. Sr. General en Jefe del Ejército Joaquín Blake; trasladándole tres días después Zappino a Gonzalo Lorenzo y Cáceres, en ese cruce de misivas, la felicitación del propio Samper para el capitán Luis de Landaburu:

Con el oficio de V.S. de 2 del actual he recibido el papel de reflexiones y croquis que ha formado el capitán del Real Cuerpo de Ingenieros D. Luis Landaburu acerca de las defensas que conviene aumentar en la Playa de Santi-Petri, a quien manifestará V.S. el aprecio que me merece el celo y aplicación con que desempeña los encargos que se le confían. Lo que traslado a $V$. a fin de que lo comunique al interesado para su inteligencia y satisfacción.

En estos primeros días del mes de mayo de 1810 se multiplicaron las comunicaciones sobre las obras de defensa, motivado, entre otras cuestiones, por la presión de los ingleses al mando del General Graham, para que se les construyera lo antes posible los reductos que habían proyectado para formar la segunda línea de defensa. En este caso, los ingenieros ingleses habían previsto en dicha zona dos reductos a retaguardia de las baterías españolas uno a la derecha y otro a la izquierda, tal y como se desprende de lo expuesto a continuación en el cruce de comunicaciones entre el Comandante de la $2^{\underline{a}}$ Brigada de Ingenieros y el propio Zappino.

\section{Gonzalo Lorenzo y Cáceres Teniente Coronel del Real Cuerpo de Ingenieros y Comandante de la $2^{a}$ Brigada destinada a las obras de defensa de la derecha de la línea y D. Pedro Salazar Sargento Mayor encargado del detall de la misma; conse- cuente con la orden que V.S. se ha servido comunicarnos en la noche de ayer, para}


que se diese principio a los reductos proyectados para los ingleses en el campo de Sancti Petri, según están indicados en el croquis o borrador que le devolvemos a V.S., hemos pasado en la mañana de hoy a dicho campo para proceder a la traza de los expresados reductos, y debemos manifestar a V.S. que luego que estén pronto los operarios con materiales y herramientas necesarias puede ya emprenderse la otra obra.

A pesar de este compromiso, los ingenieros españoles querían dedicar los escasos recursos de que disponían de material y personal en la mejora de la primera línea y posponer la construcción de los reductos ingleses. Muestra de ello se observa en este mismo informe, unas líneas más adelante en el que se expone que "hallándose estas (se refiere a nuestras baterías) en el estado tan defectuoso e incapaz de poderse oponer al ataque que intenten los enemigos por aquel punto [y] es indispensable y absolutamente preciso, que los escasos materiales de que podemos disponer, como igualmente todos los operarios, se apliquen a ejecución de las obras propuestas. No hay duda que si el Gobierno tuviese medios para proporcionar los brazos y materiales para ejecutar las dos en el mismo tiempo, seria mucho mas útil; pero como esto no es de esperar, debemos atender a las que por si solas pueden desmontar el ataque del enemigo, cuando los reductos solo pueden tener lugar contra una sorpresa". No hay lugar a dudas de que el Teniente Coronel se reafirma en sus peticiones, poniendo en segundo plano la construcción de los reductos ingleses. Sin embargo, los informes y órdenes siguen pasando por conducto reglamentario, de abajo arriba y de arriba abajo y el día 5 de mayo Manuel Zappino comunica la orden del General Blake, para la realización de las obras propuestas, así como para la construcción de "los reductos" propuestos por los ingleses para el Campo de Sancti Petri:

Habiéndose servido el Exmo. Sr. General en Gefe aprobar el aumento de defensas para las obras de la Playa de Santi Petri, con arreglo al proyecto que ha formado el Capitán del Real Cuerpo de Ingenieros D. Luis Landaburu, y determinado que además se construyan los reductos proyectados por los Ingenieros del Ejercito Británico, en las pequeñas lomas a derecha $e$ izquierda, a retaguardia de las indicadas obras, dispondrá V. lo conveniente para que a la mayor brevedad se dé principio a la construcción de los insinuados reductos, los que deberían formarse con un simple parapeto para el fusil, y su banqueta, y luego que haya los materiales necesarios para poder emprender el aumento de las obras, se dará principio a ellas procurando se vayan ejecutando por partes, de modo que no falten en aquel punto los fuegos necesarios para oponerse las tentativas de los enemigos.

Según vemos, en el proyecto original se citan al menos dos reductos ingleses, uno a la derecha y otro a la izquierda a retaguardia de las baterías, los cuáles tuvieron que ser abordados por el General Blake ante las presiones del General Graham, insistiendo en su construcción por parte del contingente español en, al menos, esta zona de la playa de Sancti Petri.

Para tratar y acordar los puntos que conviniese fortificar, y que pudiese contribuir a la mejor defensa y para concretar y consensuar todas las obras propuestas, el día 25 de junio se reunieron en casa del presidente del Consejo de Regencia, la Junta Militar, Joaquín Blake -General en Jefe del Ejército-, Nazario de Eguia -Cuartel Maestre del Ejército de Extremadura- y los comandantes Generales de Artillería e Ingenieros, en la que se acordó, que para determinar sobre el aumento de las obras en la playa de Santi Petri, y demás que conviniesen para la mejor defensa de esta Ysla, se nombrase una brigada compuesto de dos oficiales de artillería, y dos de Yngenieros a fin de que haciendo un prolijo reconocimiento en cada punto, expusiesen su dictamen, de quanto contemplasen mas útil a el expresado objeto. Esta comisión dio principio por la playa de Sancti Petri, lo que verificaron con prolijidad, manifestando en escritos del 22 de junio y 10 de julio la situación, estado, objeto y mejoras, que exigía para la perfección, y buena defensa de cada uno de los puntos, manifestado la preferencia que tenían por el proyecto de Landaburu a "todo otro que no asegurase, mas bien que el que propone este oficial, la posición de las dos orillas del citado río, satisfecho el General en Jefe de cuanto sobre el particular realizó la Brigada, dispuso que se pusiesen inmediatamente en ejecución las obras del citado proyecto, con las modificaciones que manifestó el citado militar". 
A partir de esa fecha y con no pocas dificultades a causa de la continua falta de personal y materiales se fueron construyendo las obras propuestas, aunque no con la premura esperada. Los trabajos se iniciaron con la modificación de la Batería Nueva, elevando la mampostería de la parte derecha, que pasaba en el proyecto inicial de cinco cañones en la parte alta a siete, según determinó el informe de la Brigada. A esta nueva edificación se le denominó inicialmente como Batería de Blake; y ya en noviembre de 1810 se encontraba artillada con 9 piezas de a 24 y 2 de a 16, quedando en esa fecha poco para su terminación.

De igual forma, se inició también la construcción de la batería principal que sustituiría a la batería vieja, siguiendo el proyecto de Landaburu, concretado en un plano que Zappino con fecha 29 de mayo de 1810, le envió a Blake para su mejor entendimiento:

En $1^{o}$ del corriente pasé a manos de V.E.
un papel y croquis que le acompañaba
relativo al Proyecto que formó el Capitán
del Real Cuerpo de Ingenieros D. Luis Lan-
daburu, para aumentar las defensas de
las obras en la playa de Santi Petri; y para
mayor claridad incluyo el adjunto plano
y perfil, en el que se manifiesta la dispo-
sición de la obra que se piensa ejecutar
para la formación de la principal batería
proyectada en aquel punto.

Esta batería, que se plantea como la principal de la defensa, se empezó a construir a partir de ese momento, si bien un año después solo se había construido una tercera parte. En este caso, el progreso de la obra después de un año de construcción se puede observar gracias a un plano conservado de autor anónimo y sin fecha (Archivo General Militar de Segovia. Colección: ES-DFAMD. Signatura: Carpeta 38, Plano 387. p.2), donde se observa cómo se representa construida casi un tercio de la misma, mientras que el resto se marca con línea de puntos, además de delinear la Batería Vieja con gran detalle, (Figura 8) en la que se aprecian nueve cañoneras, de las diez que tenía originalmente, aunque los informes escritos de la época la describen como una batería a barbeta, esto es, con un parapeto corrido y sin merlones.

Este plano por desgracia fue afectado por algún incendio que destruyó gran parte de los bordes del plano, donde se suele poner título, descripción, au- tor, fecha... y que de haber existido hubiera proporcionado una información más valiosa. Actualmente está catalogado con la misma signatura del que hemos reproducido en nuestra figura 5 (autoría de José del Pozo y fechado en 1797), si bien pensamos que es manifiestamente erróneo, toda vez que, mientras que la data del primero si es correcta, en el segundo se representan las baterías de Azpiroz, Urrutia y Sangenis, que como se comprueba en este trabajo, se construyeron a partir de 1810. Además, en este plano se representa el puente de barcas y las defensas de la cabeza del puente, proyectos que se realizaron a principios de marzo de 1811, durante los episodios previos a la Batalla de la Torre del Puerco o de la Barrosa, ocurrida el 5 de marzo, por lo que afirmamos sin temor a equivocarnos que la fecha de ejecución de este plano debería ser, al menos, de marzo de 1811 o posterior.

Debido a la citada falta continua de materiales y de jornales para pagar a los operarios, las obras debieron ralentizarse, mientras los responsables directos elevaban constantemente a la superioridad escritos manifestando la falta de recursos y solicitando operarios, canteros, albañiles, carpinteros, etc., que a pesar de las providencias emitidas no se presentaban a trabajar.

En este contexto, en junio de 1811 y en descargo de una queja formulada por el General Graham a la Superioridad, por la supuesta dejadez los ingenieros españoles en cuanto a la ayuda para la construcción de los reductos de la segunda línea, Manuel Zappino llega a realizar un prolijo informe de todos los motivos que fueron retrasando las obras llegando a decir en el párrafo 23 de su informe:

\section{Estoy bien persuadido que si el General} Graham asi como se halla inteligenciado del Plan de Defensa citado en el Parrafo (13) y de la utilidad de las obras propuestas en nuestros varios proyectos conferenciados con sus Yngenieros, y aun con S.E. como se tiene relacionado en los párrafos subcesivos, se hubiese hallado penetrado tambien, no solo de las continuadas reclamaciones hechas por los Yngenieros Españoles a los Generales en Gefe de este Exercito y a el Supremo Govierno, sino tambien de los entorpecimientos que a cada paso, y a pesar de las repetidas Reales Ordenes, y recomendaciones del Congreso Nacional han encontrado en la execucion y progreso de las obras, no diria 
con manifiesta equivocacion Nada concibo del modo de proceder de los Yngenieros Españoles. (Subrayado en el original) (AHN. Estado, 34, D).

De su lectura, podemos comprobar cómo, a pesar de la falta de materiales y personal, tantas veces repetidas en los informes de Zappino al General en Jefe, se fueron realizando los proyectos, siendo necesario parar algunos para poder continuar con otros más acuciantes, para después retomar los que se habían pospuesto. Como ejemplo traemos a colación la situación de la llamada Batería de la Marina -o Batería Vieja y que en algún trabajo se le ha llamado también de San Félix (Pérez, 1978: 352)-, que cómo hemos mencionado en párrafos anteriores estaba en ruinas en 1809. Dos años después quedaban en pie nueve de las diez cañoneras que tenía en un principio, y aunque sobre ella se había proyectado en 1810 la Batería de Sangenis, mientras se estaba construyendo ésta, se había artillado de nuevo y entrado en acción. Así consta en los estados de la Artillería del Cuarto Ejército, estando en uso el 1 de enero de 1812, con 7 cañones de bronce de a 24, y un mortero de 8 pulgadas; y en el estado del 1 de diciembre, cuatro meses después del levantamiento del sitio de Cádiz, todavia aparece artillada con los siete cañones de a 24 que tenía a principios de ese año, pero aunque en dichos estados se tratara como una batería independiente, en la realidad esta fortificación, formaba parte del conjunto de la Batería de Sangenis, como veremos mas adelante, y era junto a la de Urrutia, las dos que conformaban la principal defensa de la zona, tal y como menciona Toreno: "Nuestra posición en la orilla derecha dominaba la de los contrarios; $y$ dos fuertes baterías y el castillo de Sancti Petri barrían el terreno hasta las indicadas flechas" (Toreno: 1838, libro 14: 861).

Avanzando en el tiempo, entre 1812 y 1814 Carlos Vargas Machuca, realiza el Atlas de las fortificaciones de la Isla de San Fernando y fecha en enero de 1813 el estado del trazado de las bate-

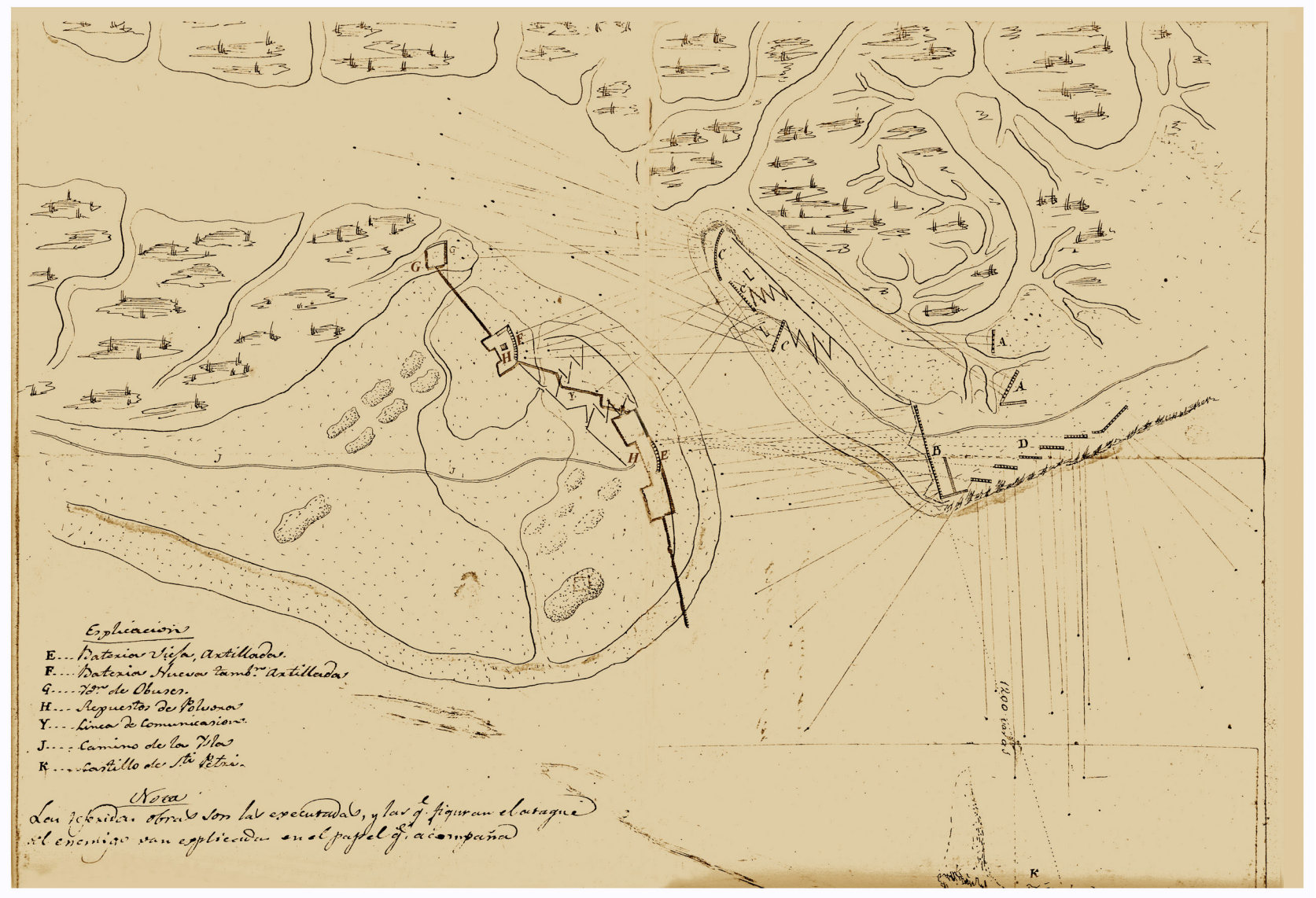

Figura 7. Croquis de Luis de Landaburu en el que se anotan los siguientes espacios Batería Vieja artillada (E), Batería Nueva también artillada (F), Id. de obuses (G), Repuestos de Pólvora (H), Línea de Comunicación (Y),Camino de la Ysla (J), Castillo de Sancti Petri (K) y se completa con la siguiente nota Las referidas obras son las ejecutadas, y las que figuran el ataque del enemigo están explicadas en el papel que acompaña. 
rías de Azpiroz, Urrutia y Sangenis, y del Reducto Inglés de Sancti Petri, dentro del capítulo de la derecha de las líneas $1^{\underline{a}}$ y $2^{\underline{a}}$ (Sancho, 2004). Hay que destacar aquí una novedad, pues ya en ese momento no se recoge la existencia de la Batería Vieja ni de un segundo reducto inglés.

De la batería de Sangenis, se ha escrito que solo se construyó un tercio de ella, quizás basándose en el comentario de Vargas, que dice "aunque en el día solo tiene en el primer tercio de la derecha solo concluido montadas catorce piezas seis de 24, dos de a 16, quatro obuses de a 9, y dos de a 7" en el que realmente no se deja claro si solo tenía concluido la tercera parte o si solo tenía catorce piezas en el tercio de la derecha. Eso sí, cabe destacar que en los informes del estado de las defensas que periódicamente se redactaban por los ingenieros responsables, se describe como se habían realizado varias reformas del proyecto original debido principalmente a la repetida falta de recursos; lo que obligó a considerar la construcción de esta batería en tres fases o tercios.

Concretamente en un informe de Zappino fechado en noviembre de 1810, sobre el estado de las defensas de Isla de León, refiriéndose a la batería de Sangenis, dice que su primer tercio se hallaba casi terminado y artillado con 6 piezas de a 24,2 de a 16 y 3 obuses de 9 pulgadas, a barbeta y termina su informe sobre ella con una nota aclaratoria: Nota: la batería vieja, que no deberá existir en concluyéndose el $2^{\circ}$ tercio de la de Sangenis, se haya en el día con siete piezas de a 24, un obús de 9 pulgadas y otro de 7 (AHN. diversos-colecciones, 120, N.2. p.14164132). En otro informe de febrero de 1811 , faltaba solo para su perfección, "hacer los merlones de ensapinado" (el ensapinado, a semejanza del adobe, era una técnica de aprovechamiento de los propios recursos naturales de la zona, en este caso fango y sapina, en vez de barro y paja), poner las banquetas para los fusileros, $\mathrm{cu}$ brir su piso de tierra, concluir un repuesto y cerrar los muros de los merlones con cantería (AHN. diversos-colecciones, 120, N.2. p.14164157). El informe seguía en el segundo tercio sobre la batería vieja, que para su conclusión "se debían elevar los muros inferiores de dicha batería con mampostería, hasta su total altura, hacer las banquetas y merlones igualmente de fango y sapina, hacer su terraplén con doce explanadas completas de madera para sus piezas y cerrar todos los muros con cantería, construyendo su repuesto de pólvora y la rampa para acceder al terraplén de las piezas". Sin embargo, nada se decía del último tercio, el cual, al parecer, en esa fecha aún no se había comenzado. Siguiendo con el relato de los hechos documentales, sabemos que el 6 de abril Manuel Zappino informó a Nazario de Eguia que las obras del $2^{\circ}$ tercio ya se hallaban en buen estado y que era conveniente concluir los merlones de las dos terceras partes antes de emprender la construcción del último tercio. Por su parte, también tenemos la información de Pérez de Sevilla, quién indica que la batería de Sangenis se terminó de construir en 1811; si bien, y como se ha indicado antes, si a finales de 1812 aún estaba en servicio la Batería Vieja, pensamos que lo que debe hacer referencia esta información es a que estaba finalizada la primera parte. Desde el levantamiento del sitio de Cádiz por los franceses en agosto de 1812, hasta la finalización de la guerra no nos consta la posible continuación de las obras de la Batería de Sangenis, sin embargo en la cartografía realizada por los ingenieros militares franceses y españoles en la bahía de Cádiz a partir de 1823, después de la rendición de Cádiz en la llamada Guerra de los cien mil hijos de San Luis o guerra realista, se dibuja la batería dividida en dos partes con los nombres de Batería Alta de Sangenis y Batería Baja de Sangenis (Figuras 9 y 10), lo que podría dar a entender que el proyecto no se concluyó según el original de Landaburu a causa, seguramente, de la repetida escasez de operarios y materiales, erigiéndose finalmente el tercio de la izquierda con la misma altura de la batería vieja.

\section{Los reductos ingleses}

De los dos reductos propuestos por los ingleses en el Campo de Sancti Petri no tenemos constancia de su completa construcción, pero sí del método propuesto y que, debido a la falta de materiales y a la premura de las órdenes recibidas, Landaburu, en un escrito dirigido al Teniente Coronel Cáceres (Archivo de la Comandancia de Ingenieros. Gobierno Militar de Cádiz. Cajón 5. Legajo 76), le propone que "el pretil que puede adoptarse en los reductos de los Ingleses, es así, poco mas o menos". En dicho escrito dibuja dos croquis (Figura 11), el primero en caso de no disponer a tiempo de cajones rellenos de tierra o mampostería, con el parapeto hecho de cestones o faginas apiladas hasta una altura de 7,5 pies ( 2 metros) y un anchura en la base de 6 y el foso con estacada en el centro, excavado en la arena con una anchura de 18 pies y una profundidad de 9 pies (aproximadamente 
unos 5 metros de ancho y 2,5 metros de profundidad), lo que haría llegar a la zona de arenas húmedas o incluso a la zona de fangos que hay debajo de la arena de playa, como así lo comenta "1ํ hasta que haya cajones [y] Esto sirve como la carabina de Ambrosio, porque como es arena movediza, ique consistencia habría de tener...?" "La carabina de Ambrosio", que no tenía pólvora en sus cañones y siempre estaba colgada de un clavo, es un antiguo dicho popular que alude a los objetos y personas que son inútiles y no sirven para nada.

A continuación, describe un segundo croquis, para el caso de disponer de los cajones " $2^{\circ}$ en viniendo los cajones [y] los triángulos rellenos de mampostería sacado después todo a plana..." Hay que destacar que, en la construcción de baterías provisionales, era habitual el empleo de cajones de madera rellenos de tierra o mampostería cuando no se disponía de piedra labrada, siguiendo los cánones de los ingenieros de la época. En el caso de estas obras citadas se utilizó el fango existente en el sustrato del terreno junto a las piedras para rellenar los cajones. Este método de montaje para los fosos también se propuso para la construcción de las baterías proyectadas, como se describe en la continuación del escrito:

Se podría usar para los fosos de las baterías el mismo método así como para su revestimiento, que sea poniendo los cajones en lugar de a lo largo, de frente, conforme a la idea aquí descrita y sacándolo todo a plana, de este método, que es baratísimo en comparación de la mampostería, se podría hacer todo el proyecto de manera productiva en pocos días, y luego cuando hubiese con qué o se determinara que habría de ser esto permanente para siempre, se podría ir haciendo de piedra.

Al final solo se debió construir un reducto como se deduce por el escrito que Nazario de Eguía, una vez finalizada la guerra, le envió el 6 de enero de 1814 al entonces Teniente Coronel del Cuerpo de Ingenieros, Pedro A. Salazar y Salazar, (que en 1810 era el Sargento Mayor del Detall de

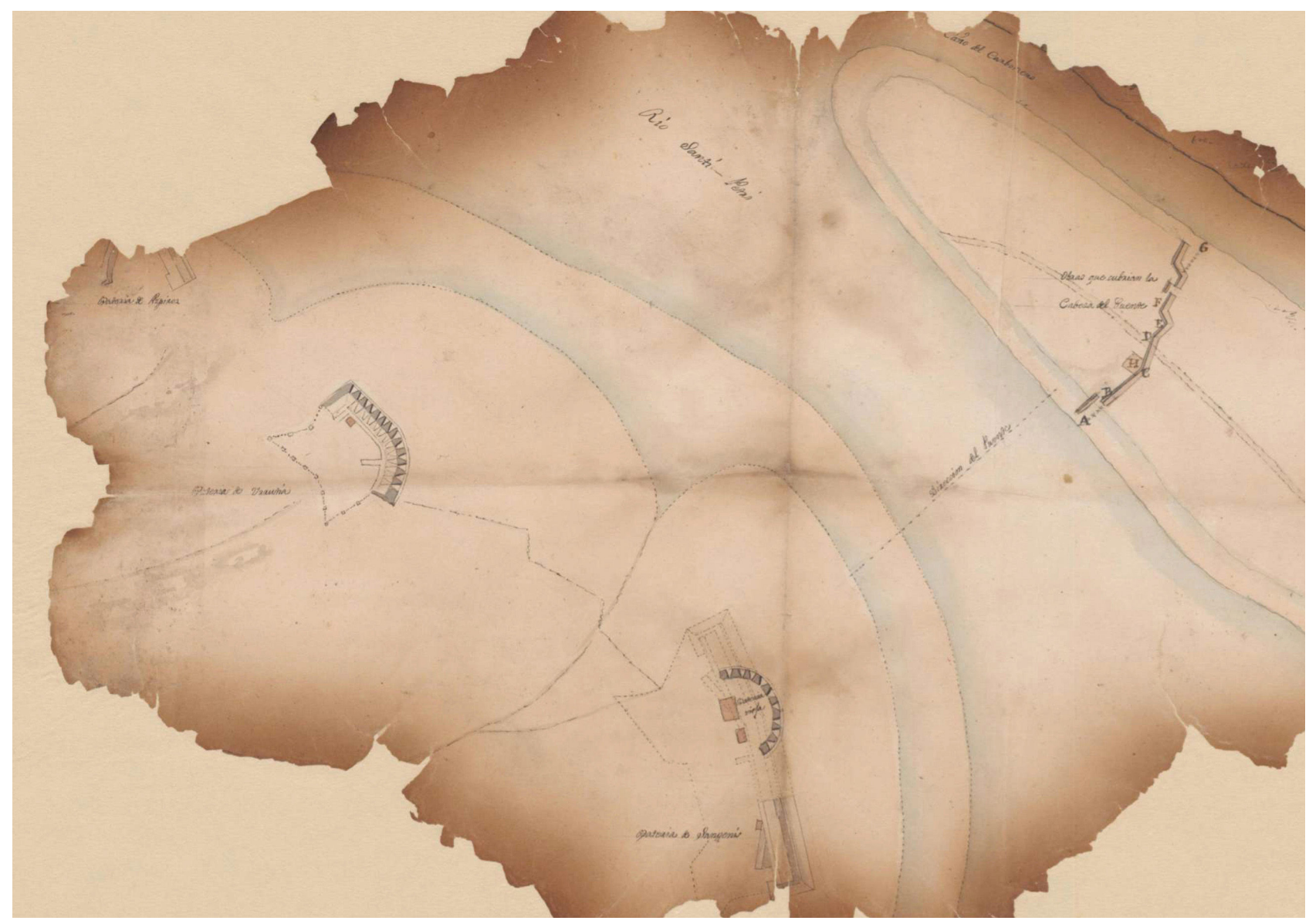

Figura 8. Plano de las defensas de la playa de Sancti Petri. (Fuente: Archivo General Militar de Segovia . Colección: ES-DFAMD. Signatura: Carpeta 38, Plano 387). 


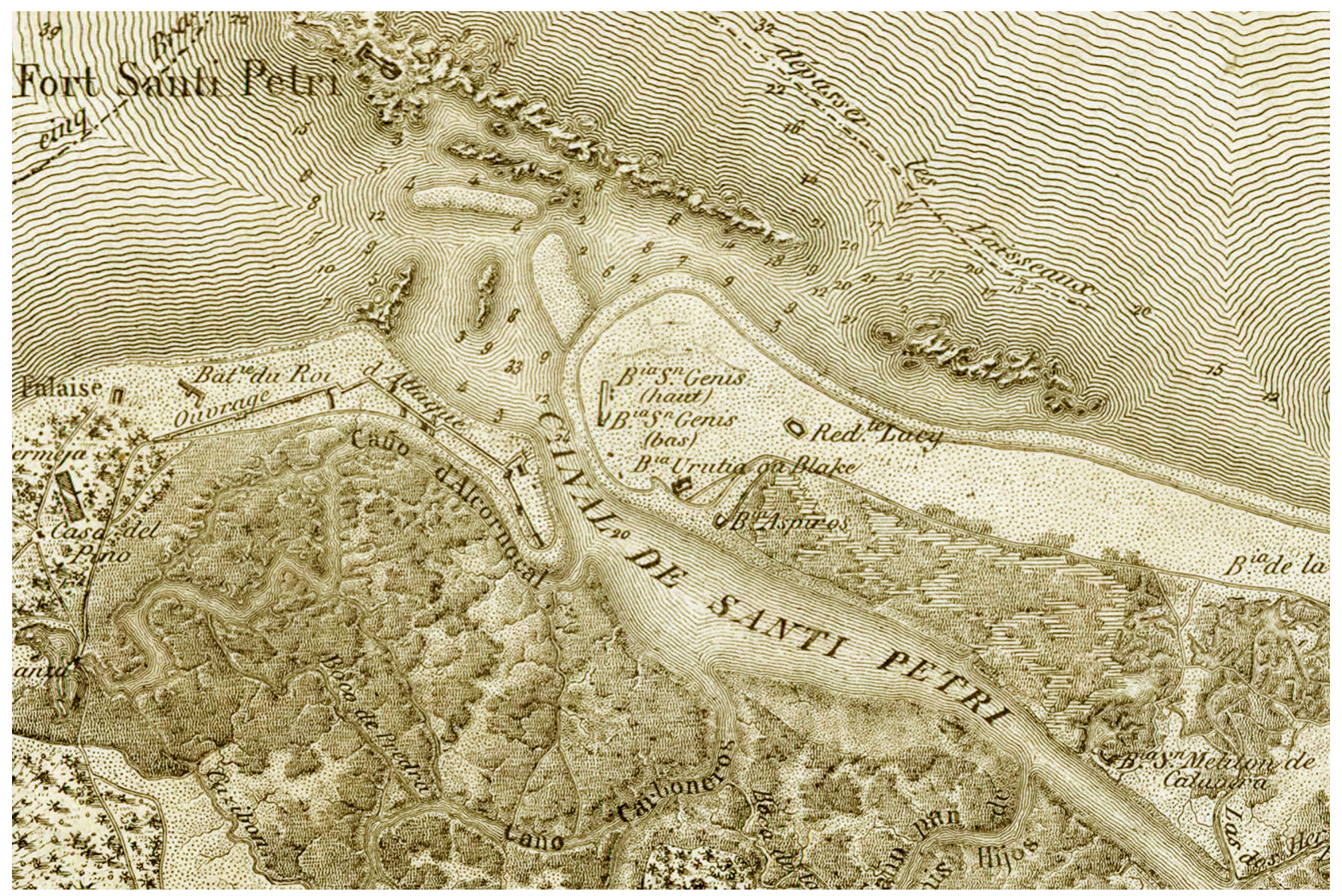

Figura 9. Detalle del Plano Plan de Cádiz et de ses environs: comprenant les travaux exécutés pendant le Siége de cette Place ainsi que les positions occupées par les Armées françaises de terre et de mar réduit d'apres celui levé a l'Echelle du 10000 par les Offrs. du Corps Royal des Ingrs. Geoges Français dans la campagne de 1823 ; dessiné sur pierre par Desmadry Jne. (Fuente: Instituto Geografico Nacional. Signatura 92-139).

la $2^{\text {a }}$ Brigada, a las órdenes del Teniente Coronel Gonzalo Lorenzo y Cáceres), informándole de la entrega del reducto por parte de los ingleses. Hay que recalcar que Nazario de Eguía era el Cuartelmaestre del Ejército de Extremadura en 1810, y acompañó al mismo a su retirada sobre las líneas de la Isla de León, contribuyó eficazmente a su defensa y fortificación, permaneciendo en el sitio hasta que los franceses levantaron el asedio en agosto de 1812. Durante este tiempo fue nombrado, en junio de 1810, Ayudante General y segundo Jefe del E. M., con destino a la misma defensa. En 1812 fue Jefe de Estado Mayor del Cantón de la Isla y Comandante General de la Isla de León y en junio de 1813 se le nombró Subinspector de Tropas de Ultramar, permaneciendo en Cádiz hasta 1815.

A las dos de la tarde del día de mañana dejan los Ingleses a mi disposición el Reducto del Campo de Santi Petri; lo manifiesto a VS para su conocimiento, y a fin de que disponga se forme un inventario de la obra, por lo perteneciente al ramo de Ingenieros.

Dios guarde a usted muchos años.

San Fernando 6 de enero de 1814.

Como vemos cita solo "el reducto", en singular; Salazar, por su parte, encargó el inventario al Subteniente de Órdenes Militares José de la Infanta, para que lo realizara en lo tocante al Ramo de Ingenieros, que lo redacta en los siguientes términos:

Inventario de los efectos que existen en el Reducto del Campo de Santi Petri, correspondiente al ramo de Fortificación.

El Reducto es de cuatro lados, revestido en lo interior de faginas, por el exterior sin ninguno. Tiene diez y seis Cañoneras, seis en el lado del E, nueve en el lado del $S$, y una en el del O. E. Las explanadas y banquetas no se ven por estar cubiertas de arena, lo mismo que la mayor parte de 


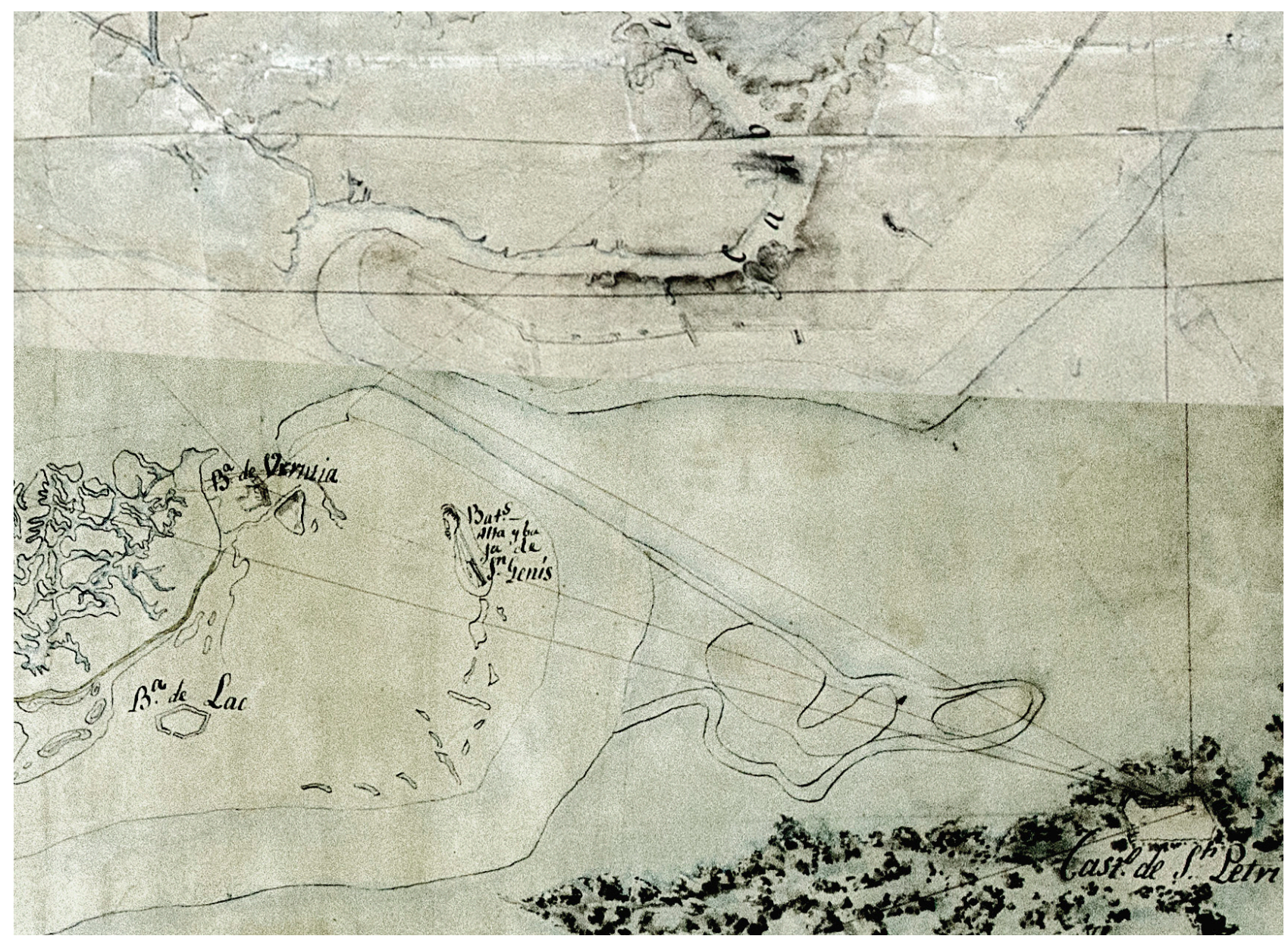

Figura 10. Detalle del Plano de la ciudad de San Fernando y del terreno adyacente que constituye la línea de defensa del frente de tierra de la isla gaditana. 1824. Manuel Varela. (Fuente: Archivo Histórico Militar de Madrid. Signatura CA-34-18).

las cañoneras.

Tiene tres cuerpos de guardia, uno de mampostería, para diez hombres, le falta la ventana, pero esta en buen uso; los otros dos en esqueleto de madera. Tiene un repuesto, a prueba de tierra, con una puerta de tablas, todo en buen estado. El foso es de agua; toda la parte de este que mira al S. está cegado de arena. Todo el Reducto necesita de mucha composición, por estar muy deteriorado.

San Fernando 8 de enero de 1814.

José de la Infanta.

Esta descripción, difiere del plano de dicho reducto que realizase Vargas Machuca dos años antes en su Atlas de las fortificaciones de la Isla de León, y aunque ambas fuentes coinciden con el número total de cañoneras, cuerpos de guardia y repuesto de pólvora, en el Atlas, el reducto apare- ce con seis lados, cuando en el inventario se citan solo cuatro lados, motivado seguramente por el mal estado en el que se recibió el reducto por la acción de los vientos y los temporales.

\section{Conclusiones}

\subsection{Batería de Azpiroz}

De esta batería actualmente no se conserva ningún resto constructivo. Su origen fue una batería de obuses hecha con cestones o faginas citada por Landaburu. Su nombre correcto es de Azpiroz, aunque se ha escrito a veces Aspiroz, por deformación fonética. Entre 1812 y 1814 Carlos Vargas Machuca, en el ya referido Atlas de fortificaciones de Cádiz con fecha en enero de 1813 presenta el estado del trazado de las baterías de Azpiroz, Urrutia y Sangenis, así como del Reducto Inglés de Sancti Petri, dentro del capítulo de la derecha 


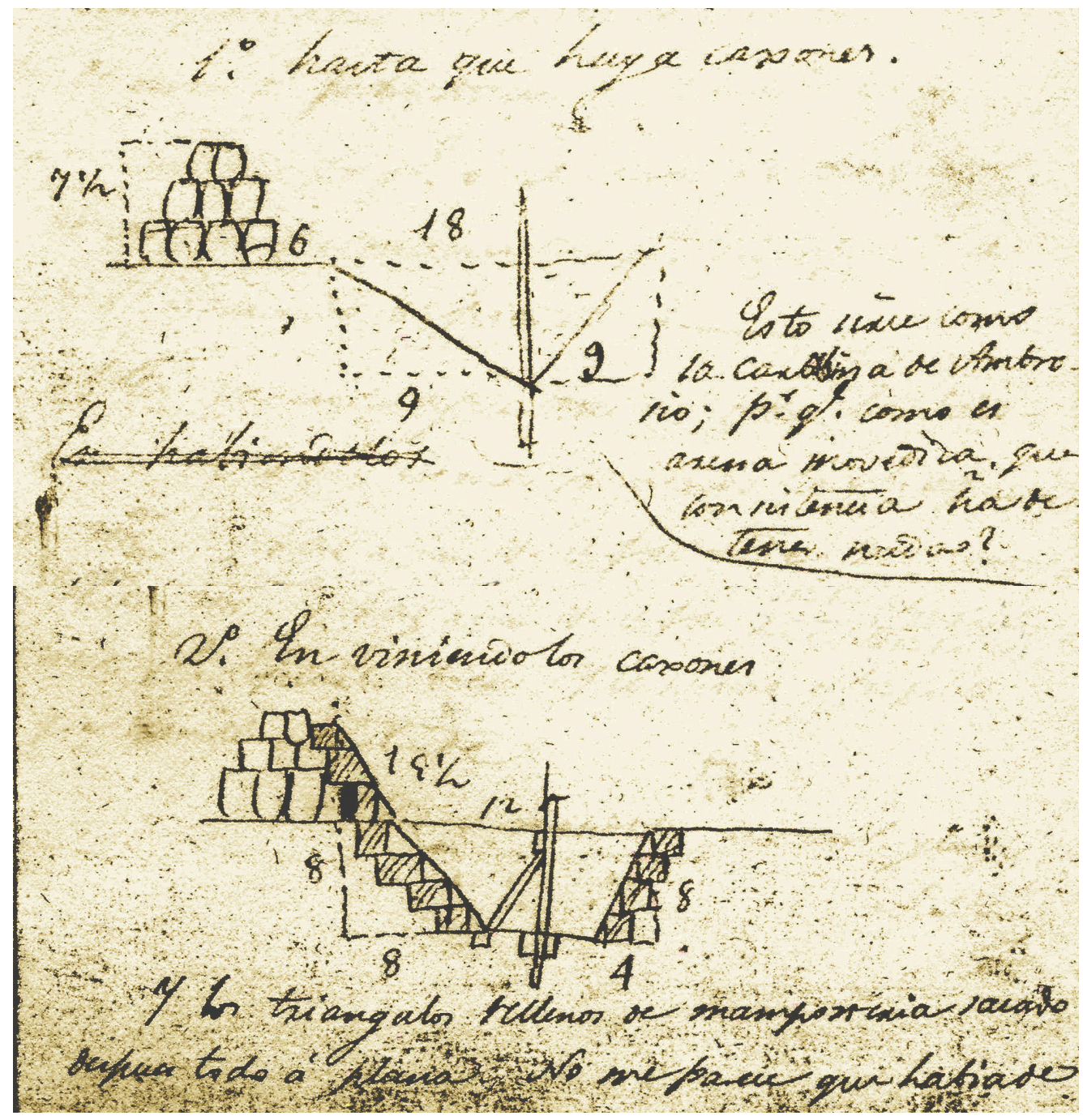

Figura 11. Detalle del croquis del escrito sin fecha del Capitán Luis Landaburu a Gonzalo Lorenzo y Cáceres, proponiendo el método para construir los pretiles de los reductos. (Fuente: Archivo de la Comandancia de Ingenieros. Gobierno Militar de Cádiz. Cajón 5. Legajo 76).

de las líneas $1^{\underline{a}}$ y $2^{\underline{a}}$; con un proyecto de mejora para esta batería que cita en sus planos, siguiendo probablemente la idea de Landaburu de elevar las baterías para poder batir mejor al enemigo; si bien como hemos podido atestiguar esto nunca llegó a realizarse (Figura 12).

Leyenda del plano de la figura 12: "Se halla establecida en el campo de Santi Petri a su izquierda en el extremo del arenal contiguo al terreno fangoso frente a la desembocadura de los Caños del Alcornocal y Carbonero. En el día solo enfila la boca de dichos Caños contra los que tiene cinco piezas del calibre de a 16, pero establecida según el plano proyecto num. 13 podría recibir el aumento de siete piezas que es indispensable para atender al Caño del Cotillo como enfilar la porción de Río y terreno que media entre ella y la de San Melitón de la Calavera, colocando las cinco piezas de a 8 en la parte baja en la que ahora están las de a 16 y estas con dos de a 8 en la parte de la Batería alta que es la que se trata aumentar en dicho proyecto y elevarla con el objeto de dominar las inmediaciones y descubrir el terreno del Cotillo para caso necesario dirigir fuegos a el. Lo dibujó el Capitán de Infantería de Línea 1ํo de Valencia. D. Carlos de Vargas Machuca Vo B $^{o}$ Eguia" (Archivo General Militar de Madrid. Ubicación: PL. Signatura: AT-9. Lámina 18).

Al igual que lo citado en el plano de Vargas, en el estado de la Artillería de 1 de enero de 1812 estaba artillada con 5 cañones de bronce de a 16. Aunque en ninguna publicación se tiene atribuido el origen del nombre de esta batería, y teniendo en cuenta que las otras dos están nominadas con nombre de militares del cuerpo 


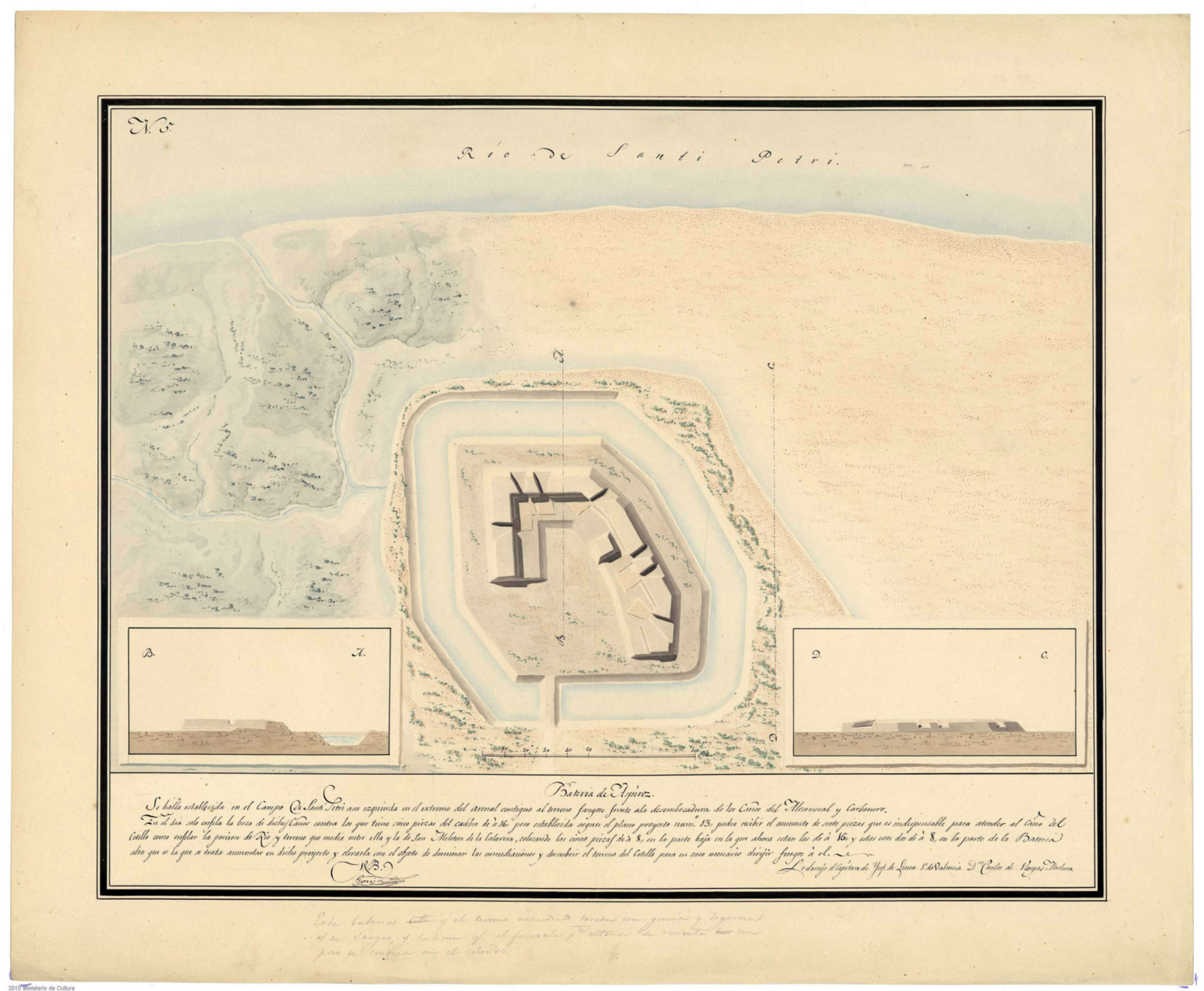

Figura 12. Batería de Azpiroz. Atlas de fortificaciones de la Isla de León. (Fuente: Carlos Vargas Machuca, Archivo General Militar de Madrid. Ubicación: PL. Signatura: AT-9. Lámina 18).

de ingenieros, ya fallecidos, a juicio de este autor el nombre de la Batería de Azpiroz, podría ser en recuerdo del Capitán del Cuerpo de Ingenieros Juan Francisco Azpiroz, muerto el 11 de noviembre de 1808 en la Batalla de Espinosa (Estado del Cuerpo de Ingenieros del Ejercito en 1887. p.10), con el Ejercito de la Izquierda, al mando del General Blake, en el que se había integrado formando parte del batallón de Ingenieros de la llamada División Expedicionaria del Norte (Gómez, 1875). Esta División se encontraba desde 1807 en Dinamarca, en función del tratado de Godoy con Napoleón, para defender las costas de un posible desembarco de las fuerzas inglesas hasta que se produjo el levantamiento del 2 de mayo, después del cual se negaron a jurar a José Bonaparte como rey de España y tras varias vicisitudes pudieron evadirse del control francés y con la ayuda precisamente de los barcos ingleses regresaron a España en octubre de 1808.

\subsection{Batería de Urrutia}

$\mathrm{Su}$ origen fue la Batería Nueva construida a principios de 1810, con un solo orden de altura de cañones y reformada a partir de abril de 1810, elevándole la parte derecha para así poder batir mejor al enemigo. Tomó en un principio el nombre de Blake y poco después el de Urrutia, conservándose actualmente en general buen estado. Tiene once troneras o cañoneras aunque en la descripción del plano de Vargas se dice que tenía trece piezas. En realidad, debió tener distribuidas las 11 piezas de a 24 repartidas entre la parte alta, (7 piezas) y la parte baja de la izquierda (4 piezas); mientras que los dos cañones de a 16 no se deja claro donde podrían haber estado, toda vez que se menciona que la barbeta de la izquierda no estaba artillada (Figura 13).

Leyenda del plano: "Situada en la playa de Sancti Petri frente la boca del caño del Alcornocal tiene por objetos, descubrir toda la playa de su izquierda a la parte del Castillo, para lo que tiene una barbe- 


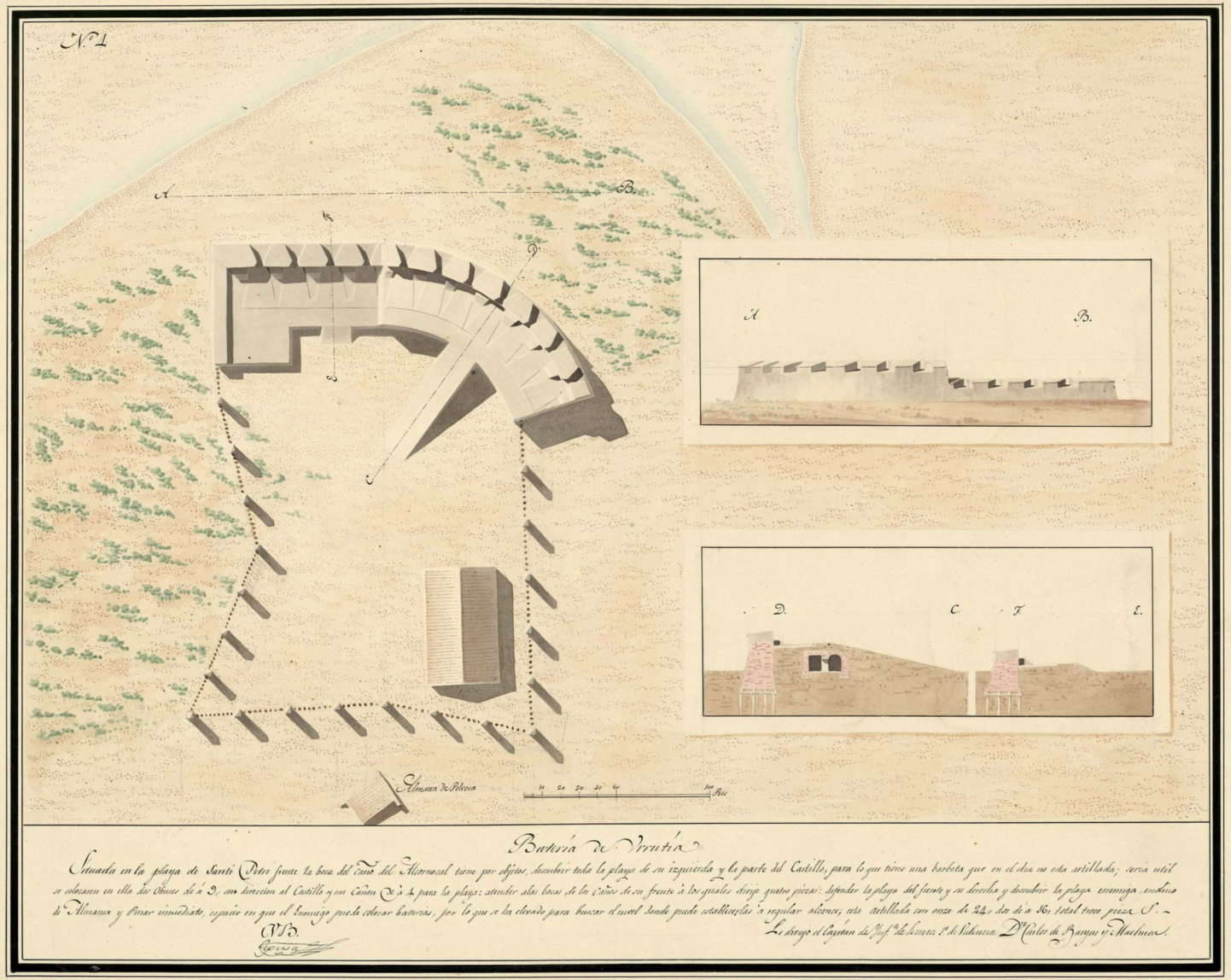

Figura 13. Batería de Urrutia. Atlas de fortificaciones de la Isla de León. (Fuente: Carlos Vargas Machuca, Archivo General Militar de Madrid. Ubicación: PL. Signatura: AT-9. Lámina 40).

ta que en el día no está artillada; sería útil se colocasen en ella dos Obuses de a 9 con dirección al Castillo y un cañón de a 4 para la playa; atender a las bocas de los Caños de su frente a los quales dirige quatro piezas; defender la playa del frente y su derecha y descubrir la playa enemiga, molino de Almansa y Pinar inmediato, espacio en que el Enemigo puede colocar baterías, por o que se ha elevado para buscar el nivel donde puede establecerlas a regular alcance; esta artillada con onze de 24, dos de a 16,, total trece piezas. Lo dibujo el Capitán de Infantería de Línea $1^{o}$ de Valencia. D. Carlos de Bargas y Machuca Vo Bo Eguia" (Archivo General Militar de Madrid. Ubicación: PL. Signatura: AT-9. Lámina 40).

El nombre de la batería se le dio en memoria del general José de Urrutia y de las Casas, que había fallecido el 1 de marzo de 1803, Urrutia fue Ingeniero General del Ejército español, cargo desde el que dio vida al Cuerpo de Ingenieros Militares.

\subsection{Batería de la Marina}

Su origen fue la batería construida junto al paso de barcas por la Marina en 1762 como defensa de costa para proteger la entrada del Caño de Sancti Petri. A lo largo de su existencia se han referido a ella como Batería de la Marina, Batería de la Voca del Río, Batería de la Barca, Batería arruinada, Batería Vieja y Batería de San Félix. Con la continuación de la construcción de la batería de Sangenis probablemente fue absorbida dentro de la misma. Proponemos que un estudio en profundidad sobre el terreno podría aportar más datos, aunque toda esta parte está actualmente cubierta por una gran duna.

\subsection{Batería de Sangenis}

Proyectada en 1810 y construida entre ese año y 1813, la Batería toma el nombre de Sangenís, (citada en varios planos como San Genís) en memoria del Coronel Ingeniero Antonio de Sangenís y 


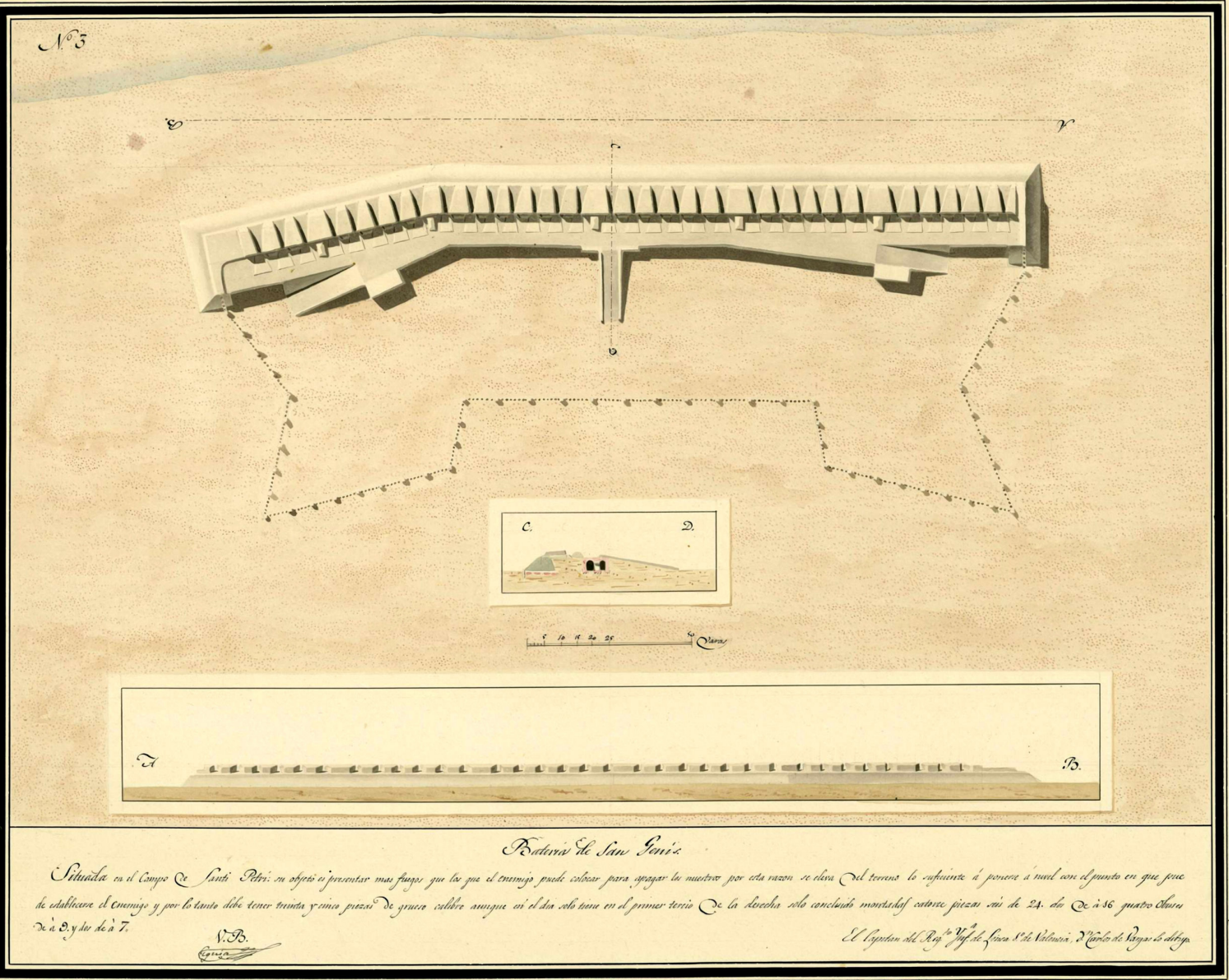

Figura 14. Batería de Urrutia. Atlas de fortificaciones de la Isla de León. (Fuente: Carlos Vargas Machuca, Archivo General Militar de Madrid. Ubicación: PL. Signatura: AT-9. Lámina 28).

Torres, distinguido en los Sitios de Zaragoza, donde falleció el 12 de enero de 1809 a consecuencia de un disparo de cañón del enemigo (Figura 14).

Vargas la describe en su Atlas con la siguiente leyenda: "Situada en el Campo de Santi Petri: su objeto es presentar mas fuegos que los que el enemigo puede colocar para apagar los nuestros por esta razón se eleva del terreno lo suficiente para ponerse a nivel con el punto que puede establecerse el enemigo y por lo tanto debe tener treinta y cinco piezas de grueso calibre aunque en el día solo tiene en el primer tercio de la derecha solo concluido montadas catorce piezas, seis de a 24, dos de a 16 quatro obuses de a 9, y dos de a 7. Lo dibujo el Capitan del Regimiento de Infanteria de Línea $1^{\circ}$ de Valencia, $D$. Carlos de Vargas Machuca. Vo $B^{o}$ Eguia" (Archivo General Militar de Madrid. Ubicación: PL. Signatura: AT-9. Lámina 28).

Teniendo en cuenta la escala de 50 Varas indicada en dicho plano, que equivalen a 41,75 metros, si aplicamos la misma podemos ver como el con- junto completo de la batería tendría 250 varas de largo (209 metros). Haciendo una superposición a escala del plano de Vargas sobre la ortofoto de la zona y tomando como referencia los restos visibles actualmente, como lo son, la zona del polvorín y la rampa de subida de la derecha, podemos comprobar como la parte izquierda sobresaldría del complejo dunar que la cubre unos 50 metros. Si nos detenemos en la cartografía de la época, la orilla del caño se encontraba a casi 90 metros de distancia agua dentro de la actual. La pérdida de arena causada por la erosión y sobre todo por su extracción antrópica, ha producido el retroceso de la orilla derecha del caño en este punto. Como consecuencia, los restos de la batería han ido perdiendo su sustentación por lo que se ha ido destruyendo poco a poco. Así, actualmente se constatan en superficie unos 20 metros de restos de muros dispersos por la playa, que indudablemente pertenecen a la batería (Figura 15).

Podría pensarse que pudieran pertenecer a la 


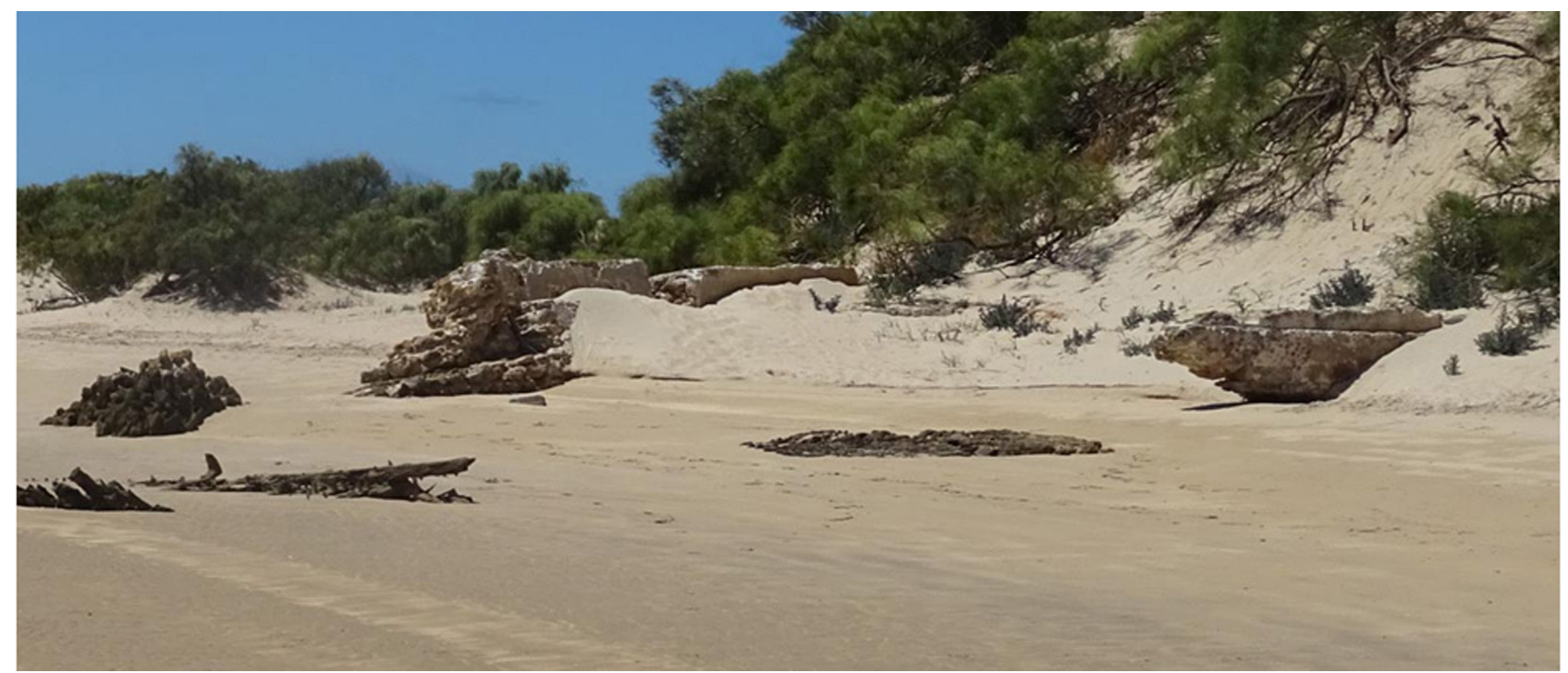

Figura 15. Restos constructivos de la Batería de Sangenis erosionados en la playa. (Fuente: Fotografía del autor. 2020).

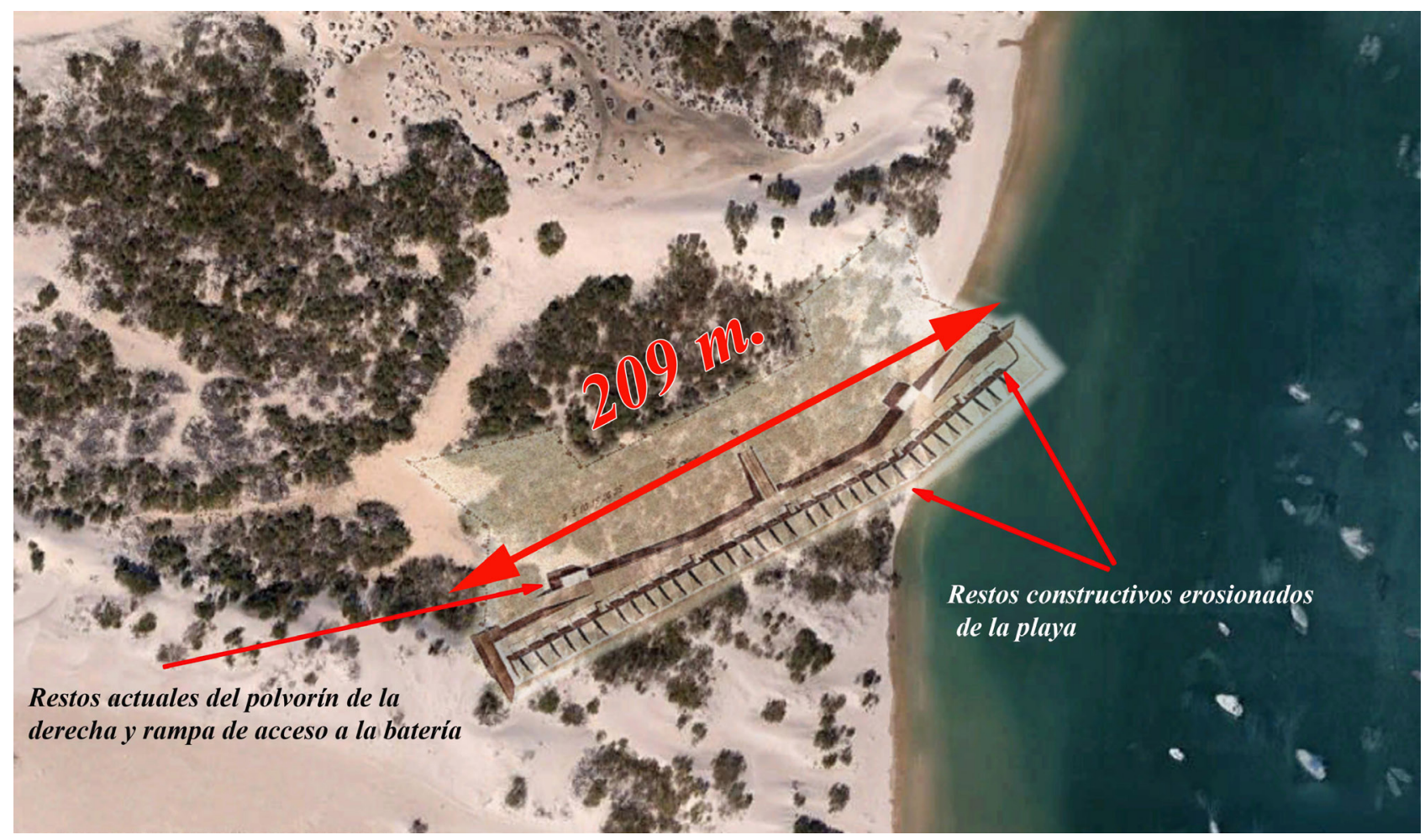

Figura 16. Geolocalización de la batería de Sangenis. (Fuente: Montaje del autor sobre captura de Google Earth).

Revista Atlántica-Mediterránea de Prehistoria y Arqueología Social 22, pp. 373-398 
antigua batería de marina o de la barca, pero esta era de construcción circular y los restos visibles son de construcción lineal y, además, siguen la misma dirección que la indicada tanto en el proyecto de Landaburu como en el plano de Vargas, lo que también nos da una idea más clara del cambio de la línea de costa en estos últimos doscientos años.

En la siguiente imagen (Figura 16) se ha colocado el plano de Vargas escalado con la ortofoto, capturada de Google Earth, donde se aprecian los detalles comentados.

Esta fortificación se debió terminar con una variación sobre el proyecto original, con dos órdenes de altura de cañones; la batería alta y la batería baja aprovechando los restos de la Batería Vieja. Actualmente se pueden observar bastantes restos constructivos que afloran sobresaliendo del complejo dunar que la cubre siguiendo la enfilación y ángulo que debería formar la parte izquierda de la misma, pero con las cañoneras a una altura menor que las de los restos conservados de la batería alta en el interior de la zona dunar y que podrían pertenecen a los restos de la denominada posterior- mente como batería baja de Sangenis. No obstante, se podrían completar los estudios de esta batería si se llevara a cabo el proyecto de recuperación de estas defensas que se presentó con motivo de los actos del Bicentenario de la Cortes.

\subsection{Reductos ingleses}

Del proyecto original de dos reductos, finalmente sólo se construyó uno en la parte derecha de la posición, en principio solo con un pretil para fusileros y posteriormente se mejoro para artillarlo con 16 cañones. Denominado como Reducto Inglés de Sancti Petri o de Lacy, fue construido por los españoles como hemos podido comprobar y no por los ingleses, como a veces se ha publicado. De acuerdo con el plano de Vargas, en 1812, tendría unas medidas de 120 metros de ancho y 82 metros de fondo, que aproximadamente son las dimensiones de un campo de fútbol, lo que da idea de la capacidad de tropa que podría albergar. En este caso, solo la dotación de artilleros de las 16 piezas de grueso calibre que había en el mismo, podría rondar los 150 hombres.

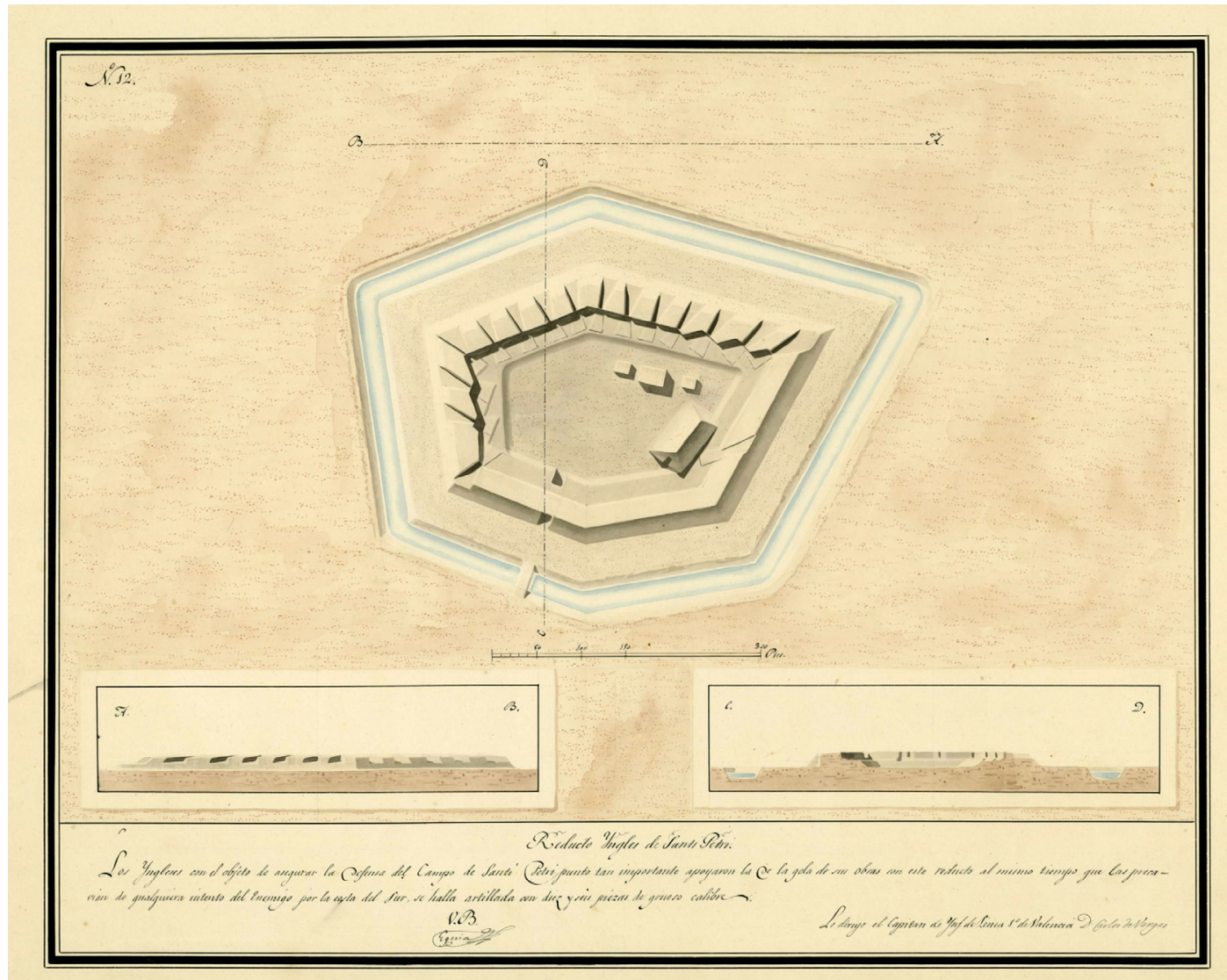

Figura 17. Reducto Ingles de Sancti Petri. Atlas de fortificaciones de la Isla de León. (Fuente: Carlos Vargas Machuca, Archivo General Militar de Madrid. Ubicación: PL. Signatura: AT-9 Lámina 45). 
"Reducto Ingles de Santi Petri. Los ingleses con el objeto de asegurar la defensa del campo de Santi Petri, apoyaron la de la gola de sus obras con este reducto al mismo tiempo que precavían de qualquier intento del enemigo por la costa del sur, se halla artillada con dieciséis piezas de grueso calibre. Lo dibujo el Capitán del Regimiento de Infantería de Línea $1^{o}$ de Valencia, D. Carlos de Vargas Machuca. $V^{o} B^{o}$ Eguia" (Archivo General Militar de Madrid. Ubicación: PL. Signatura: AT-9. Lámina 45).

Insistimos en el dato sobre la representación en el plano de Vargas Machuca (Figura 17) de una planta en hexágono irregular, mientras que en la descripción del Inventario que hemos mencionado en apartados precedentes se indica que tenía cuatro lados. Eso sí, tanto el plano como el inventario coinciden en que tenían dieciséis cañoneras. Terminamos mencionando cómo los restos de este reducto aparecieron en la playa de Campo Soto en 2010, después de un temporal en el que se retiró toda la arena y se pudieron ver los restos del foso y parte de la estructura del interior; precisamente Antonio Sáez Espligares tuvo la fortuna de poder fotografiar y estudiar estos restos (Figura 18), que posteriormente fueron cubiertos nuevamente por la acción de las mareas.

\section{Bibliografía}

AHN, Diversos-Colecciones,108, N.37.

AHN. DIVERSOS-COLECCIONES, 120, N.2.

AHN. Estado, 34, D.

CARRILLO DE ALBORNOZ Galbeño, Juan. 2008: Ingenieros Ilustres del S. XVIII (Parte II). Memorial del Arma de Ingenieros. Núm. 80.

CASTRO, Adolfo de. 1864: Cádiz en la Guerra de la
Independencia: Cuadro histórico. Excelentísimo Ayuntamiento de Cádiz. Cádiz.

CASTRO, Adolfo de. 1858: Historia de Cádiz y su provincia: desde los más remotos tiempos hasta 1814. Diputación Provincial de Cádiz. Cádiz.

Estado del Cuerpo de Ingenieros del Ejercito en 1887. p.10. Biblioteca Central Militar. Signatura: P-1869.

GÓMEZ DE ARTECHE Y MORO, José. 1875: Guerra de la Independencia. Imprenta y litografía del Depósito de la Guerra. Madrid.

PÉREZ DE SEVILLA Y AYALA, Vicente. 1978: La artillería española en el sitio de Cádiz. Instituto de Estudios Gaditanos, Diputación Provincial de Cádiz. Cádiz.

QUEIPO DE LLANO, José María (TORENO, Conde de). 1838: Historia del Levantamiento, Guerra y Revolución de España. Tomo II. Libro 14: 861. QUINTERO GONZÁLEZ, José. 2010: "El Bloqueo de la Isla de León, 1810-1812". XXXVI y XXXVIII Jornadas de Historia Marítima. Cuaderno Monográfico. Ministerio de Defensa.

SÁEZ ROMERO, Antonio Manuel; DÍAZ RODRÍGUEZ, José Juan. 2012: "Entre tierra y mar. Entre lo púnico y lo romano. Adaptaciones económicas y territoriales en un medio cambiante: algunas notas sobre la paleogeografía y sistemas de explotación del hinterland insular de Gadir/Gades". En B. MORA y G. CRUZ (coords.): La etapa neopúnica en Hispania y el Mediterráneo centro occidental: identidades compartidas, pp. 259-299. Secretariado de Publicaciones Universidad de Sevilla. Sevilla.

SANCHO RODA, José. 2004: El atlas de las fortificaciones de la Isla de San Fernando de Carlos Vargas Machuca. Ayuntamiento de San Fernando.

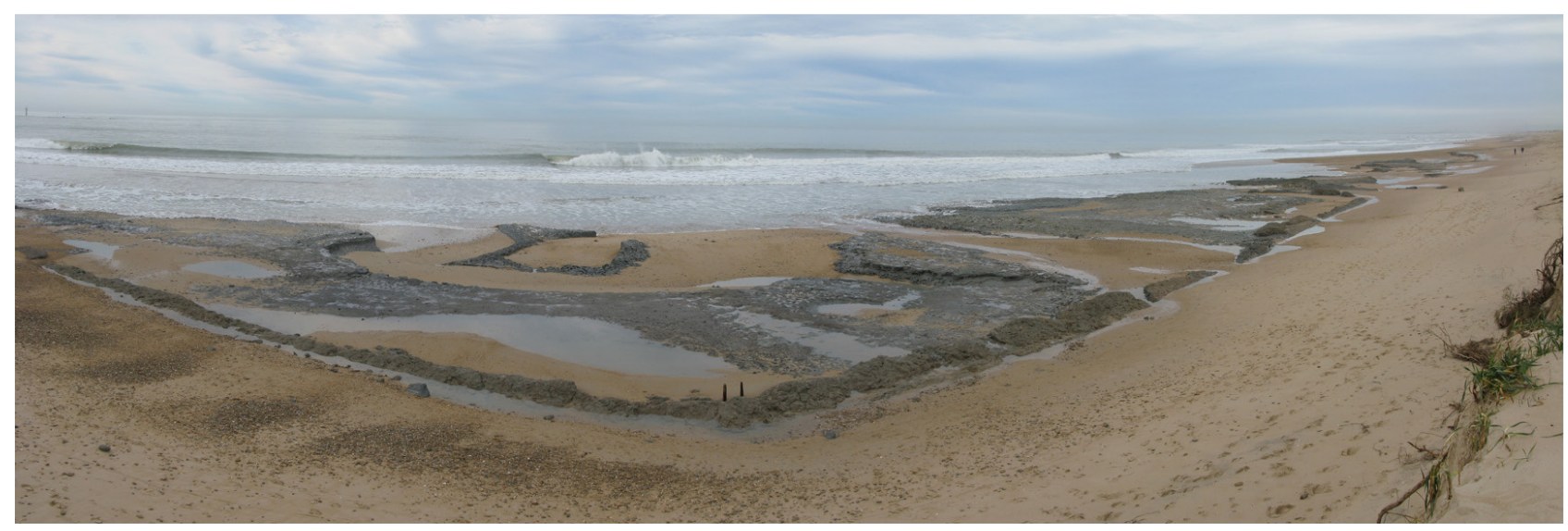

Figura 18. Restos del Reducto inglés o de Lacy, aparecidos en la playa de Camposoto, como consecuencia de los temporales del Octubre de 2004. (Fuente: Saez y Díaz, 2012: 288, fig. 11aㅡ). 
S.H.M. Servicio Histórico Militar. 1972: Guerra de la Independencia. Editorial San Martín. Madrid.

TORREJÓN CHAVES, Juan. 2008: "El sitio francés de la isla de león (1810-1812)". Revista General de Marina, 255, pp. 349-374.

Relación de fuentes documentales empleadas en el presente estudio pertenecientes al Archivo de la Comandancia de Ingenieros. Gobierno Militar de Cádiz. Cajón 5. Legajo 76:

- $\quad$ Estudio de fecha 29 de abril de 1810 del Capitán Luis Landaburu, sobre la defensa de la playa de Sancti Petri.

- Escrito de fecha 30 de abril de 1810, de Gonzalo Lorenzo y Cáceres a D. Manuel Zappino, remitiéndole el estudio del Capitán Luis Landaburu, con la petición de elevarlo al General en Jefe de este Ejercito.

- Escrito de fecha 2 de mayo de 1810, (copia sin firma) a Don Antonio Samper, remitiéndole copia de los documentos del proyecto de Luis Landaburu para su conocimiento.

- $\quad$ Escrito de fecha 2 de mayo de 1810, de Gonzalo Lorenzo y Cáceres y Pedro Antonio Salazar, informando sobre la orden de realizar los reductos de los ingleses.

- $\quad$ Escrito de fecha 3 de mayo de 1810 de D. Manuel Zappino en el que traslada el del Teniente Coronel Gonzalo Lorenzo y Cáceres, sobre los proyectos de defensa del Campo de Sancti Pe- tri al Exmo. Sr. General en Jefe del Ejército D. Joaquín Blake.

- Escrito de fecha 5 de mayo de 1810, de Manuel Zappino a Gonzalo Lorenzo y Cáceres, trasladando la felicitación de D. Antonio Samper al Capitán Landaburu por su estudio que le envío con fecha 2 del corriente.

- Escrito de fecha 5 de mayo de 1810 (copia sin firma), a Gonzalo Lorenzo y Cáceres comunicando la aprobación de las obras propuestas por Luis Landaburu y la realización de las obras de los reductos de los Ingleses.

- Escrito de fecha 5 de mayo de 1810, de Manuel Zappino a Gonzalo Lorenzo y Cáceres comunicando la aprobación de las obras propuestas por Luis Landaburu y la realización de las obras de los reductos de los Ingleses.

- $\quad$ Escrito de fecha 5 de mayo de 1810 de D. Manuel Zappino a D. Gonzalo Lorenzo y Cáceres, dando recibo al documento que este le envío con el estudio del Capitán Luis Landaburu, informando de su felicitación.

- Escrito de fecha 8 de mayo de 1810 (copia sin firma) al General Joaquín Blake, solicitando autorización para realizar las obras propuestas por Landaburu así como otras para completar la defensa de la zona del Cerro de los Mártires.

- Escrito de fecha 29 de mayo de 1810, de Manuel Zappino al General D. Joaquín Blake, remitiéndole plano y perfil, de la principal bate-

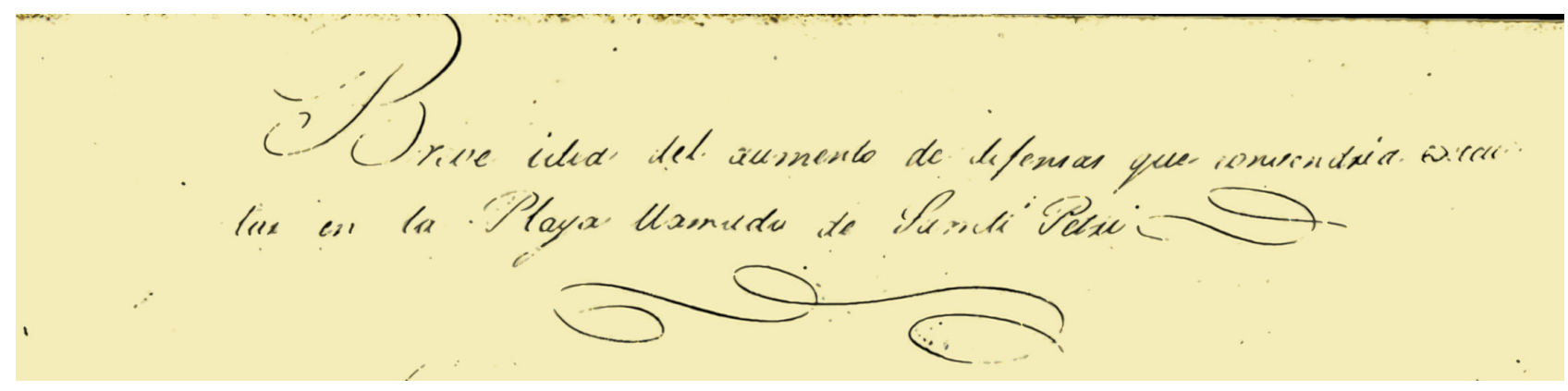

ría que se proyecta.

- Escrito sin fecha del Capitán Luis Landaburu a Gonzalo Lorenzo y Cáceres, proponiendo el método para construir los pretiles de los reductos.

- Escrito de fecha 6 de enero de 1814, de Nazario de Eguia a Antonio Salazar y Salazar, informándole de la entrega de los reductos por parte de los Ingleses.

- Inventario de fecha 8 de enero de 1814 del reducto Ingles del Campo de Santi Petri que realiza José de la Infanta.

\section{Anexo}

Transcripción literal del informe del Capitán Luis Landaburu, sobre la defensa de la playa de Sancti Petri de fecha 29 de abril de 1810:

Breve idea del aumento de defensa que convendría ejecutar en la Playa llamada de Sancti Petri.

Si para obrar con acierto en la ofensiva, y dirigir 
los ataques con la seguridad y firmeza necesarias, es preciso un conocimiento detallado y reflexivo de las defensas que se pretenden superar, igual noticia se necesita en la defensiva, para oponer de antemano al temido ataque los obstáculos propios a hacerlo infructuoso. Imaginar pues, el modo con que podrá uno ser atacado y de quien inferir el de defenderse, es el medio mas natural de proceder debidamente en la disposición de una defensa.

Es claro que la facilidad que tenemos de pasar el Sancti Petri proviene de la posesión en que nos hallamos de ambas orillas; una por nuestra real estancia en ella; la otra por la superioridad de nuestros fuegos que impiden al enemigo el acercarse. Si este consiguiere hallarse en otro caso, efectuaría su paso como y cuando quisiese, y a esto debe dirigirse sus miras. Nuestra defensa como se halla hoy día, consiste principalmente, en la Artillería del Castillo de Sancti Petri que flanquea el camino de Chiclana, en la batería vieja y las cañoneras. Pues las otras dos baterías no pueden usar sus fuegos con el acierto necesario para detener las obras enemigas, y la trinchera únicamente puede servir contra sorpresas, pues nunca serán tan necios los enemigos que vengan a ponerse bajo el fuego del fusil, ni se acercaran a orilla opuesta que ocupan, sin dominar la nuestra con fuegos muy superiores, y tales que no nos permitan acercarnos a ella. El ataque pues debería dirigirse así- 1ำ Precaverse contra las salidas que de aquí pudieran hacerse -2º Espaldonarse contra el fuego de la batería vieja y cañoneras - $3^{o}$ Construir en toda la playa una batería considerable que precise a callar los fuegos del castillo, cuya construcción no le es tan fácil a este el impedir por la mucha distancia a que se halla. 4o Posesionarse del Caño del Molino con una fuerte batería construida en A. $5^{\circ}$ A favor de estos fuegos construir la batería B, en el paso B que proporciona colocación para 25 o 30 piezas, con la que bien pronto se haría callar la batería vieja, se batiría todo el Campo, y se haría ya muy sangrienta la estancia en el. 6 $\mathrm{A}$ favor de estos fuegos, construir las baterías $C$ acabar de arruinar las nuestras y precisarnos a retirarnos de la orilla, alejando con esta superioridad de fuegos las fuerzas sutiles que se les quisieran oponer. Dueños ya de ambas orillas, 7ํㅡㄴificar el paso.

Este es el orden general del ataque que pudiera emprenderse para el paso del río, en cuyos detalles omito porque hablo con inteligentes. Es preciso confesar que los trabajos serán de lenta y sangrientísima ejecución; pero también es preciso decir que no por eso se debe pensar que no puedan ejecutar- se. Resueltos los enemigos a atacarnos, no repararan ciertamente en el tiempo que hayan de atacar tardar, y tienen los recursos de toda especie tan a mano que abreviarían demasiado. El solo pinar del Coto les puede dar cuanto necesiten para sus obras, y conducida la construcción de estas con talento y vigor no es tan lenta como de pronto parece. Toda la formidable artillería de un Gibraltar, no impidió colocar contra la plaza más de 250 piezas, y Mantua aunque rodeada de pantanos impracticables ( $\mathrm{sin}$ más avenidas que estrechas calzadas) vio colocar fuertes baterías de brecha en su glacis.

De la exposición de este ataque se colige, que la batería decisiva es la $B, y$ por consiguiente que el conato principal de la defensa debe ponerse en impedir su construcción, lo cual no puede conseguirse sino aumentando la batería vieja hasta hacerla superior o a lo menos igual en fuegos a que pueda colocar el enemigo en $B$, pues por la elevación de este punto es de poco efecto el fuego de las cañoneras. No será pues en balde, el trabajo y cuidado que se empleen en aumentar la batería vieja, que se debe considerar como decisiva en la defensa, y este aumento deberá llevarse al punto de montar en ella 30 o 35 piezas, y elevarla 12 o 15 pies para que domine con facilidad el terreno que ha de batir. El espesor de sus parapetos deberá ser de 21 pies; su revestimiento el ordinario de plaza, y su gola deberá cerrarse; en una palabra, debe ser una obra capaz de llenar el grande objeto al que se destina. La batería nueva tiene dos objetos, batir el Caño del Molino y la avenida de Chiclana. El $1^{\circ}$ lo llene debidamente; pero no así el $2^{\circ}$ por su cortísima elevación. Se deberán pues elevar las cinco primeras piezas destinadas a este objeto, hasta conseguir el fin propuesto; esto es, unos 10 pies. La batería de obuses, no puede coadyuvar a el sino con fuegos inciertos por su elevación, cuya razón empeña tanto mas el aumento de la batería vieja, pues llegada, repito a construirse la batería enemiga $B$, la de las demás es consiguiente.

Tan fácil como espaldonarse contra los fuegos de la batería vieja en el estado en que se halla al presente, por su cortísima elevación, y colocar de consiguiente la batería B superior en fuegos contra el Castillo, tan sangriento y terrible seria para el emprender esta operación bajo el fuego de la nueva batería según la propongo; no seria posible hacerlo a cuerpo descubierto, tendría que principiar su obra a alguna distancia, se vería reducido a perder continuamente gente en la reparación de su espaldón, y estaría si cesar expuesto por la elevación dada a la batería al ver rebotada la suya de contra el Castillo, 
sufriendo de todas maneras el incesante y acertado fuego de obús que pudiera hacérsele.

Igual ventaja proporciona el aumento y elevación de esta batería, contra la construcción de la A que ha de dominar el Caño de el molino: en el estado presente ni aun la descubre; pero su principal servicio es contra la $B$, que tal vez de este modo jamás llegaría a establecerse, pues siendo inferior en piezas (aun suponiéndola ya construida) debería ceder a la nuestra. Ahora bien antes de llegar a estarlo ique de tiempo y sangre costaría al enemigo, i y llegada a construir podrá destruir la nuestra con fuegos directos y horizontales, habiendo de obrar contra un parapeto de 21 pies ¿ Seria fácil verificarlo? Pues con el estado en que al presente se halla, ocioso es decir que nada seria más fácil. Estas razones tan poderosas, a mi parecer, unidas a la reflexión de que no se trata de una defensa de tiempo determinado, sino de hacer esta inexpugnable, es lo que me mueve a proponer en la batería vieja el considerable aumento expresado.

La batería nueva y la de obuses convendría estuviesen cerradas en los términos que la batería vieja, y rodearlas de foso y estacada para el caso posible aunque remotísimo de una sorpresa. Todas se deberían unir con una línea bien construida con su estacada, y esta debería continuarse en la baja mar hasta la profundidad de dos varas y media, con lo cual quedaría una línea continua cuyos flancos estarían perfectamente apoyados.

Es de indispensable y urgente necesidad, espaldonar por de pronto el campamento de la tropa, continuando la comunicación de la batería nueva a la vieja por la derecha, hasta que quede cubierto el Campo, y llenarlo todo de dados para sortear las granadas, que impunemente podrá arrojar el enemigo cuando quiera; y digo por el pronto, porque concluidas las obras deberá trasladarse el Campo fuera del tiro del cañón enemigo, sin quedar en la línea y baterías mas que la guarnición necesaria; pues por mas espaldones que se construyan, en caso de ya de un ataque es difícil evitar continuas desgracias, y cuando no la inquietud e incomodidades que son consiguientes a un fuego vivo y continuado.
Una división de obuseras, que calando poca agua son muy a propósito para introducirse por el Caño del Molino, u otra de cañoneras para dominar de flanco el Río, son indispensable y completarían el sistema general permanente de esta playa.

Esta es la idea general de aumento de defensas, que me sugiere mi cierto talento para este puesto, de cuyas obras estoy encargado. Lejos de mi la necia presunción de pensar que mis ideas sean las ciertas; sé muy bien que puedo haberme equivocado, y sujeto muy gustoso mi dictamen al examen y critica de mis compañeros; pero en lo que creo mi pensamiento mas aproximado a la verdad, es en el aumento que propongo de la Batería vieja, el cual pido se examine detenidamente, pues considero esta batería como la mas interesante en la defensa, y la única que puede obrar segura y continuamente contra los trabajos que el enemigo puede ejecutar para el ataque de este punto; por que el Castillo se halla muy distante, y las fuerzas sutiles, expuestas a mil contratiempos y dificultades pueden únicamente contribuir a la defensa; pero de ninguna manera decidirla.

Campo de Sancti Petri a 29 de Abril de 1810.

Luis de Landaburu. 